\title{
Effect of emissions inventory versus climate model resolution on radiative forcing and precipitation over the continental United States
}

\author{
R. C. Owen ${ }^{1,2}$ and A. L. Steiner ${ }^{1}$ \\ Received 20 April 2011; revised 17 November 2011; accepted 20 December 2011; published 1 March 2012.
}

[1] We evaluate the impact of anthropogenic emission inventory and climate model grid resolution on aerosol concentrations and black direct aerosol top of atmosphere forcing. Anthropogenic aerosol concentrations of sulfate, black carbon (BC), and organic carbon (OC) are simulated using a high-resolution $(25 \mathrm{~km})$ regional climate model (RegCM) with (1) the $20001^{\circ} \times 1^{\circ}$ EDGAR inventory and (2) the $19994 \mathrm{~km}$ U.S. Environmental Protection Agency (EPA) National Emissions Inventory. A third $60 \mathrm{~km}$ EPA simulation tests the effect of climate model resolution. Simulated $\mathrm{SO}_{2}$ and $\mathrm{SO}_{4}^{2-}$ concentrations from the $25 \mathrm{~km}$ simulations agree with observations in DJF, but JJA modeled $\mathrm{SO}_{2}$ is high and $\mathrm{SO}_{4}^{2-}$ is low by a factor of 2-3 suggesting incomplete sulfate conversion in the model. Simulated $\mathrm{BC}$ and $\mathrm{OC}$ concentrations are lower than observations, and sensitivity tests suggest the inventories are missing carbonaceous sources. Total aerosol optical depth (AOD) is greater than observations in DJF and lower in JJA, confirming an underestimation of aerosols during summertime. Derived top of atmosphere radiative forcing has a maximum JJA decrease of 7, 8, and $10 \mathrm{~W} / \mathrm{m}^{2}$ in the EDGAR, EPA $25 \mathrm{~km}$, and EPA $60 \mathrm{~km}$ simulations, respectively. Generally, the $60 \mathrm{~km}$ simulations improve measured-modeled aerosol agreement due to reduced precipitation and wet deposition in the $60 \mathrm{~km}$ simulation. Comparisons with observations indicate that total precipitation in the $60 \mathrm{~km}$ simulation is closer to observations. Thus, aerosol forcings from a regional model may be equally sensitive to resolution and emissions inventory due to the parameterization of large-scale precipitation and wet removal processes.

Citation: Owen, R. C., and A. L. Steiner (2012), Effect of emissions inventory versus climate model resolution on radiative forcing and precipitation over the continental United States, J. Geophys. Res., 117, D05201, doi:10.1029/2011JD016096.

\section{Introduction}

[2] Atmospheric aerosols modify the global energy balance by absorbing and scattering radiation (the direct effect) and by modifying the optical and physical properties of clouds and the frequency of precipitation (the indirect effect) [Intergovernmental Panel on Climate Change (IPCC), 2007]. At the global scale, the net effect of aerosols on climate is a reduction in the top of the atmosphere forcing of $0.5[ \pm 0.4] \mathrm{W} \mathrm{m}^{-2}$ for direct effects and $0.7[1.8-$ $0.3] \mathrm{W} \mathrm{m}^{-2}$ for indirect effects [IPCC, 2007]. However, the level of understanding of the role of aerosols in climate is relatively low compared to many of the other components of the global energy balance. Despite having somewhat short lifetimes (hours to days), reductions in aerosols are expected to enhance global warming [Shindell et al., 2008] and

\footnotetext{
${ }^{1}$ Department of Atmospheric, Oceanic, and Space Sciences, University of Michigan, Ann Arbor, Michigan, USA.

${ }^{2}$ Now at Michigan Tech Research Institute, Michigan Technological University, Ann Arbor, Michigan, USA.

Copyright 2012 by the American Geophysical Union. 0148-0227/12/2011JD016096
}

influence surface temperature trends [Shindell and Faluvegi, 2009].

[3] Aerosols are emitted from a wide variety of natural (e.g., volcanic activities, sea spray, and wind-borne dust) and anthropogenic sources (e.g., fossil fuel burning and industrial activities). Techniques and inventories implemented for aerosol modeling depend on the time scale in question, ranging from detailed aerosol schemes in regional chemical transport models to address short-term air quality events [e.g., Qian et al., 2010] to simplified aerosols schemes designed for global, long-term climate simulations [e.g., Hansen et al., 2007a]. However, the high resolution leads to computationally expensive simulations that are not suitable for long-term (e.g., decadal scale) climate simulations. In contrast, global circulation models (GCMs) employ simplified chemical parameterization for aerosols and are more frequently employed in the study of aerosol/climate interactions [e.g., Hansen et al., 2007b]. GCM simulations with aerosols are usually at a fairly coarse resolution $\left(2^{\circ} \times\right.$ $2.5^{\circ}$ and greater) and thus also tend to use coarse resolution inventories, such as the $1^{\circ} \times 1^{\circ}$ EDGAR inventory [Olivier et al., 2005; van Aardenne et al., 2005]. Coarse resolution simulations often have difficulty capturing local and 
Table 1. Wet and Dry Removal Parameterizations for the Six Aerosol Species

\begin{tabular}{lccc}
\hline \multicolumn{1}{c}{ Species } & $\begin{array}{c}\text { Fraction of } \\
\text { Tracer } \\
\text { Dissolved }\end{array}$ & $\begin{array}{c}\text { Dry Deposition } \\
\text { Velocity } \\
(\text { Land, cm s }\end{array}$ & $\begin{array}{c}\text { Dry Deposition } \\
\text { Velocity } \\
\text { (Water, cm s }\end{array}$ \\
\hline $\mathrm{SO}_{2}{ }^{\mathrm{a}}$ ) & 0.20 & 0.30 & 0.80 \\
$\mathrm{SO}_{4}^{2-}$ & 0.80 & 0.20 & 0.20 \\
$\mathrm{BC}_{h b} / \mathrm{OC}_{h b}{ }_{h b}^{\text {b,c }}$ & 0.05 & 0.25 & 0.25 \\
$\mathrm{BC}_{h l} / \mathrm{OC}_{h l}{ }^{-1}$ & 0.80 & 0.025 & 0.20 \\
\hline
\end{tabular}

${ }^{\text {a }}$ Taken from Tan et al. [2002].

${ }^{\mathrm{b}}$ Taken from Cooke et al. [1999].

${ }^{c}$ Hydrophobic.

${ }^{\mathrm{d}}$ Hydrophilic.

regional scale simulations that may be influenced by aerosols (e.g., monsoon regions [Ramanathan et al., 2005]). To overcome this difficulty, higher resolution limited area, regional climate models (RCMs) have been developed to address the climatic impact of aerosols at finer model resolution [Tan et al., 2002; Ekman and Rodhe, 2003; Pal et al., 2009].

[4] Because the climate impacts of aerosols are known to exhibit strong spatial heterogeneities [e.g., National Research Council, 2005; Matsui and Pielke, 2006], regional climate simulations may provide a better estimate of the regional aerosol-climate feedbacks than GCMs and highlight resolution dependent processes. For example, increased resolution improves regional circulation and precipitation patterns in RCMs [e.g., Pal et al., 2009; Walker and Diffenbaugh, 2009; Rauscher et al., 2010], suggesting that higher resolution studies with aerosols may be necessary. While some studies have shown that different model resolutions can significantly impact the results for CTMs and GCMs [e.g., Wild and Prather, 2006; Bian et al., 2009; Qian et al., 2010; Stroud et al., 2010; Appel et al., 2010], relatively few comparisons have been done to examine the effect of inventory and model resolution on aerosol-induced climate changes. Here, we address the question of the emission inventory and climate model resolution by comparing the impact between (1) two different resolution emission inventories (EPA NEI and EDGAR) and (2) two regional model resolutions $(25 \mathrm{~km}$ versus $60 \mathrm{~km}$ ) using the NEI inventory on the modeled TOA and precipitation.

\section{Methods}

\section{1. $\operatorname{RegCM}$}

[5] We evaluate the impact of aerosol emissions on climate using the Abdus Salam International Centre for Theoretical Physics (ICTP) RegCM climate model version 3 [Pal et al., 2009, and references therein]. RegCM is a grid point limited area model based on the NCAR/Pennsylvania State University hydrostatic mesoscale model MM4 [Grell et al., 1994]. Land surface processes are represented by the Community Land Model version 3.5 [Lawrence and Chase, 2007; Steiner et al., 2009] and boundary layer physics are parameterized by the non-local scheme of Holtslag et al. [1990]. Moist convection is modeled with the Grell [1993] scheme with the Fritch-Chappell closure, and large-scale precipitation is parameterized using the subgrid explicit moisture scheme (SUBEX) [Pal et al., 2000]; these specific precipitation schemes were selected based on previous
RegCM model evaluations over the continental U.S. [Walker and Diffenbaugh, 2009]. Radiative transfer is described using the radiation package of the NCAR Community Climate Model, version CCM3 [Kiehl et al., 1996]. Initial and lateral atmospheric boundary conditions, which are updated every 6 hours in the simulations, are derived from the NCEP reanalysis [Kalnay et al., 1996], which has a $2.5^{\circ} \times 2.5^{\circ}$ horizontal resolution with 17 pressure levels every 6 hours. Chemical boundary conditions are not provided for these continental-scale simulations. Weekly sea surface temperatures are derived from the NOAA Optimum Interpolation SST V2 data set [Reynolds et al., 2002] for the duration of the model simulation.

\subsection{Aerosol Model}

[6] The aerosol model is based on the $\mathrm{SO}_{2} / \mathrm{SO}_{4}^{2-}$ parameterization of Qian et al. [2001] and the black carbon (BC) and organic carbon (OC) parameterization of Solmon et al. [2006]. Simplified chemistry for long-term chemistryclimate simulations models BC and OC in two bulk forms: a hydrophobic (hb) and hydrophilic (hl) state. Thus, our simulations carry a total of six tracers: $\mathrm{SO}_{2}, \mathrm{SO}_{4}^{2-}, \mathrm{BC}_{h b}$, $\mathrm{BC}_{h l}, \mathrm{OC}_{h b}, \mathrm{OC}_{h l}$. The prognostic equation used to determine the mass mixing ratio $\left(\chi^{i}, \mathrm{~g} / \mathrm{kg}\right)$ of each species is given by:

$$
\begin{aligned}
\frac{\delta \chi^{i}}{\delta t}= & -\bar{V} \cdot \nabla \chi^{i}+F_{H}^{i}+F_{V}^{i}+T_{C}^{i}+S^{i} \\
& -R_{w, l s}^{i}-R_{w, c}^{i}-D_{d}^{i}+\left(Q_{p}^{i}-Q_{l}^{i}\right),
\end{aligned}
$$

where $\bar{V} \cdot \nabla \chi^{i}$ is advection, $F_{H}^{i}$ and $F_{V}^{i}$ are horizontal and vertical turbulent diffusion, and $T_{C}$ is the convective transport [Qian et al., 2001; Solmon et al., 2006]. Each transport term is identical to that used for the cloud water mixing ratio in the MM5 [Grell, 1993; Qian and Giorgi, 1999], and assumes the tracer becomes well mixed between cloud base and cloud top during convection [Kasibhatla et al., 1997]. $S$ is the surface emission, which is discussed further in section 2.3.

[7] Scavenging via large scale and convective precipitation ( $R_{w, l s}^{i}$ and $R_{w, c}^{i}$, respectively) is based on the cloudwater to rainwater conversion rate [Giorgi, 1989; Giorgi and Chameides, 1986]. This rate is explicitly calculated for resolved clouds and specified for cumulus clouds, according to the grid cell cloud fraction [Pal et al., 2000] and the fraction of tracer dissolved in available cloudwater [Solmon et al., 2006] (values in Table 1). Rainwater is immediately precipitated out of the column and thus the model does not allow for aerosols to be re-released by the evaporation of rainwater. Dry deposition $\left(D_{d}^{i}\right)$ is parameterized by assuming constant deposition velocities, with different values prescribed over land and water (Table 1).

[8] The conversion of $\mathrm{SO}_{2}$ to $\mathrm{SO}_{4}^{2-}$ (production and loss due to physical and chemical transformations, $Q_{p}^{i}$ and $Q_{l}^{i}$, respectively) occurs via gas phase and aqueous phase reactions [Qian et al., 2001]. Gas phase $\mathrm{SO}_{2}$ is oxidized by $\mathrm{OH}$ to form sulfate and in this study we assume oxidation by ozone is negligible [Rasch et al., 2000; Giorgi et al., 2002]. In these simulations, we use monthly mean global $\mathrm{OH}$ fields on a $2.8125^{\circ}$ grid from a global chemical transport model simulation (MOZART [Emmons et al., 2010]) with 26 
Table 2. Emission Rates for the Three Primary Aerosol Species Summed Over the Model Domain $(\mathrm{kg} / \mathrm{s})^{\mathrm{a}}$

\begin{tabular}{lcccccc}
\hline Species & EPA Area & EPA Point & EPA Total (Native) & EPA Total $(25 \mathrm{~km})$ & EDGAR Total (Native) & EDGAR Total (25 km) \\
\hline $\mathrm{SO}_{2}$ & 72.72 & 488.45 & 561.17 & 558.41 & 676.33 & 645.99 \\
$\mathrm{BC}$ & 13.82 & 1.21 & 15.03 & 15.00 & 12.38 & 11.74 \\
$\mathrm{OC}$ & 19.68 & 5.47 & 25.15 & 25.06 & 18.24 & 17.38 \\
\hline
\end{tabular}

${ }^{a}$ Because the regridding process is not mass-conservative, we include the total mass of the native (original resolution) and regridded ( $25 \mathrm{~km}$ and $\left.60 \mathrm{~km}\right)$ data sets.

vertical levels. A superimposed diurnal cycle varies $\mathrm{OH}$ concentrations to be close to zero at night [Solmon et al., 2006]. MOZART4 OH concentrations are estimated to be slightly lower than other climatological $\mathrm{OH}$ fields [Emmons et al., 2010] and may lead to an underestimate of $\mathrm{SO}_{2}$ oxidation. In the aqueous phase, conversion occurs by the dissolution of $\mathrm{SO}_{2}$ to form $\mathrm{HSO}_{3}^{-}$and $\mathrm{SO}_{3}^{-2}$ ions, which are then oxidized by $\mathrm{H}_{2} \mathrm{O}_{2}$. In these simulations, as in the work of Giorgi et al. [2002], we assume that there is sufficient $\mathrm{H}_{2} \mathrm{O}_{2}$ in the model [Kasibhatla et al., 1997] and do not use simulated $\mathrm{H}_{2} \mathrm{O}_{2}$ concentrations to drive the aqueous oxidation. Due to large uncertainties in the transformations of carbonaceous aerosols, we use a simple aging scheme which converts the hydrophobic state to the hydrophilic state (e.g., $\mathrm{BC}_{h b}$ to $\left.\mathrm{BC}_{h l}\right)$ using an exponential lifetime $\left(\tau_{a g}=\right.$ 1.15 d) [Cooke et al., 1999; Solmon et al., 2006].

[9] The RegCM simulations in this study account for aerosol direct effects only. The online tracer model described in equation (1) determines a concentration in space and time, and these concentrations are provided to the online radiative transfer model. Each aerosol species can scatter (all species) and absorb (black carbon only) incoming solar radiation, which in turn impact the thermodynamic profile of the atmosphere. These thermodynamic changes can affect vertical mixing, the parameterization of precipitation, the processing of aerosols and the resulting column burden. We note that the model does not include any explicit treatment of the indirect effect, such the effect of aerosol concentration on cloud droplet number concentration or the precipitation efficiency. Therefore, any changes to precipitation are a result of from thermodynamic effects only and not the indirect effect of aerosols.

\subsection{Emissions}

[10] For the model simulations presented here, we evaluate the changes in radiative forcing and precipitation using two inventories with different resolutions. We use a high resolution $(4 \mathrm{~km})$ inventory based on the U.S. Environmental Protection Agency (EPA) 1999 National Emissions Inventory (NEI), which includes primary aggregate area and point source emissions of summertime anthropogenic $\mathrm{SO}_{2}$, BC and OC [Frost et al., 2006; Kim et al., 2009]. The NEI inventories include (1) fossil fuel usage, such as power production and ground transportation, (2) biofuel usage including agricultural crop burning, and (3) most industrial facilities in the U.S. The EPA $\mathrm{SO}_{2}$ emissions are dominated by fossil fuel combustion sources (approximately 89\%) followed by industrial processes (6\% [U.S. Environmental Protection Agency, 2011]). The second, low resolution inventory $\left(\mathrm{a} 1^{\circ} \times 1^{\circ}\right.$ horizontal grid) based on the global EDGAR 3.2 Fast Track 2000 inventory for $\mathrm{SO}_{2}$ [Olivier et al., 2005; van Aardenne et al., 2005] and the Bond et al. [2007] and Fernandes et al. [2007] 2000 BC and OC emissions. The EDGAR inventory includes predominantly the same source categories as the NEI inventories with the addition of shipping emissions. In the following discussion, the low resolution inventories collectively are referred to as the EDGAR emissions set. Table 2 summarizes the emissions inventories over the model domain and primary emissions are shown in Figure 1. The inventories as implemented in RegCM for these simulations do not include any seasonal or interannual variability. Emissions are based on anthropogenic emissions only and thus notably exclude several important sources, including biomass burning, biogenic emissions, sea salt aerosol and dust. Based on a comparison of CTM simulations and ground-based aerosol measurements, Park et al. [2003] estimated that these missing biogenic and wildfire sources account for approximately $11 \%$ of all black carbon emissions and $55 \%$ of all organic carbon emissions for 1998.

[11] Upon release, $\mathrm{SO}_{2}$ emissions are initially split between $\mathrm{SO}_{2}$ and $\mathrm{SO}_{4}^{2-}$, with $98 \%$ in the gas phase and $2 \%$ converting directly to the particulate phase [Qian et al., 2001]. Similarly, primary BC and OC emissions are split between the hydrophobic and hydrophilic forms. For BC, $80 \%$ of the primary emissions are in the form of $\mathrm{BC}_{h b}$ and $20 \%$ are in the form of $\mathrm{BC}_{h l}$, while $\mathrm{OC}$ emissions are split equally between $\mathrm{OC}_{h b}$ and $\mathrm{OC}_{h l}$.

[12] In both emission inventories, primary $\mathrm{SO}_{2}$ emissions are greatest over the eastern half of the continent and relatively low in the non-coastal western U.S., driven by the population density and the prevalence of coal-fired power plants (Figures 1a and 1b). The domain-averaged emissions are similar in magnitude and spatial distribution, yet the EDGAR emissions are $15 \%$ greater than the EPA, with EDGAR $\mathrm{SO}_{2}$ emissions up to $0.1 \mathrm{~kg} \mathrm{~m}^{-2} \mathrm{~s}^{-1}$ higher in the eastern half of the U.S. (Table 2 and Figure 1c). Despite having a similar total emission rate, the EDGAR emissions visually appear to be much greater than the EPA emissions. This is driven by the dominance of point sources in the EPA emissions, which typically only occupy one grid cell and thus do not show the broader spatial effect as in the EDGAR emissions.

[13] $\mathrm{BC}$ emissions have a spatial distribution similar to $\mathrm{SO}_{2}$, with high emissions in the Ohio River Valley and major metropolitan areas due to coal-fired power plants and diesel emissions (Figures 1d and 1e). Relative to $\mathrm{SO}_{2}, \mathrm{BC}$ emissions are greater on the west coast. EPA BC emissions are generally higher in the Ohio River Valley and central northern U.S., while EDGAR emissions are higher elsewhere (Figure 1f), leading to a higher estimate of $\mathrm{BC}$ emissions in the EPA inventory (Table 2). Similar to BC, anthropogenic OC emissions are also concentrated in the eastern U.S., but with greater emissions outside the Ohio River Valley, particularly in the southeastern U.S. (Figures $1 \mathrm{~g}$ and $1 \mathrm{~h}$ ). The EPA emissions are generally stronger than the EDGAR 

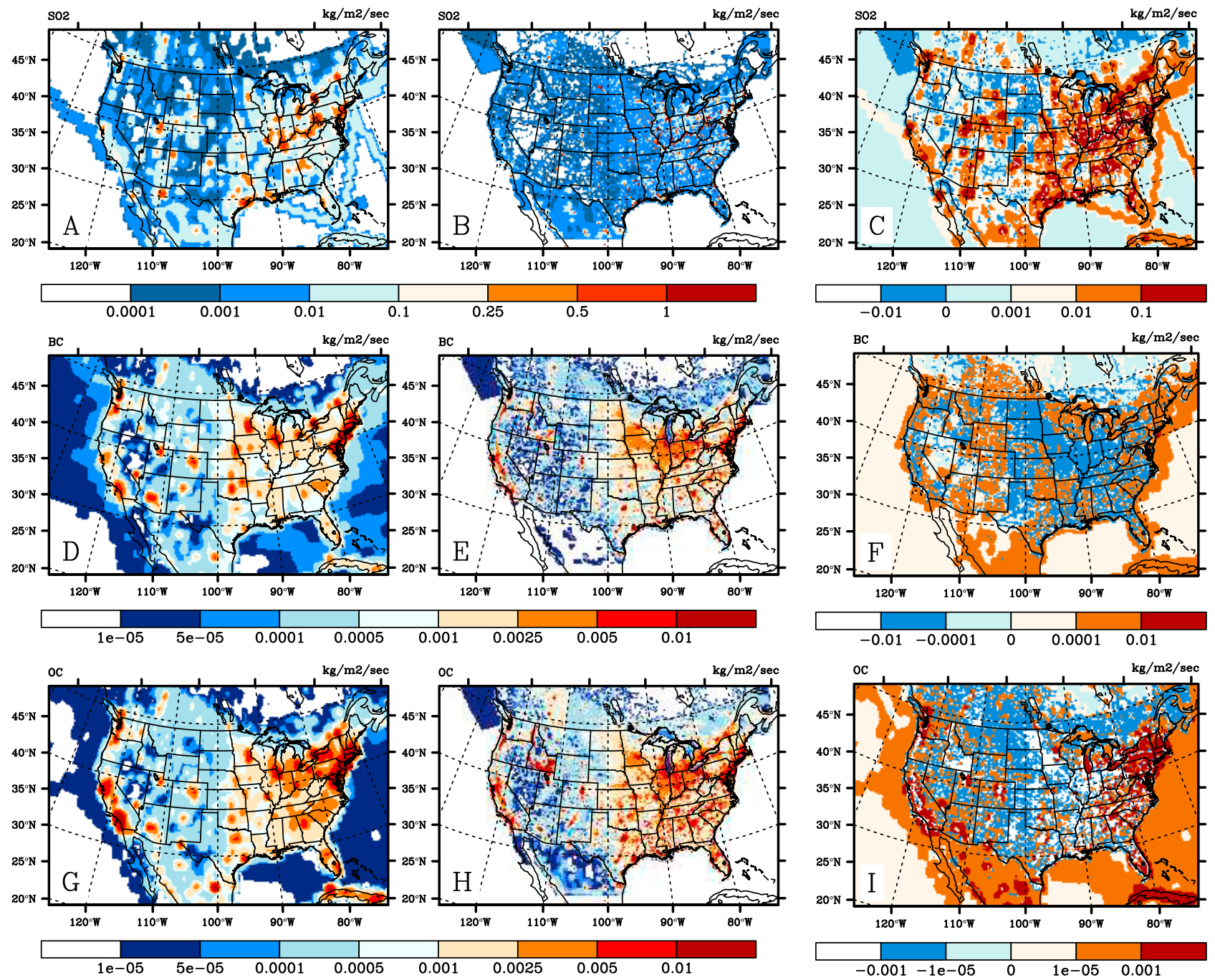

Figure 1. Spatial distribution of $(\mathrm{a}-\mathrm{c})$ anthropogenic $\mathrm{SO}_{2}(\mathrm{~d}-\mathrm{f})$ black carbon $(\mathrm{BC})$, and $(\mathrm{g}-\mathrm{i})$ organic carbon (OC) emissions for the EDGAR $25 \mathrm{~km}$ (ED; Figures 1a, 1d, and 1g) and EPA NEI $25 \mathrm{~km}$ (EP; Figures 1b, 1e, and $1 \mathrm{~h}$ ) simulations, and emission differences (ED-EP) for $\mathrm{SO}_{2}$ (Figure 1c), $\mathrm{BC}$ (Figure 1f), and OC (Figure 1i).

emissions over the central U.S. (Table 2), but weaker along the west coast and in the northeastern U.S. (Figure 1i).

\subsection{Experiment Design}

[14] For this study, we perform two high resolution (25 $\mathrm{km}$ ) climate simulations focused on the continental United States using a Lambert conic conformal map projection, centered on $39^{\circ}$ North and $100^{\circ}$ West with a 224 grid cells in the east-west direction and 145 cells in the north-south direction. These two simulations include six aerosol species, with one simulation based on the EPA emissions (EP), and one simulation based on the EDGAR emissions (ED). Aerosol emissions do not take into account any trends or seasonal variability and are kept constant throughout the simulation.

[15] We also conduct a coarse resolution $(60 \mathrm{~km}$; EPC) simulation which is identical to the EP simulation except for the resolution of the model grid. The coarse resolution simulations use the same model domain, but at a $60 \mathrm{~km}$ resolution (96 longitudinal cells, 61 latitudinal cells) and implement the EPA NEI emissions inventory. The $60 \mathrm{~km}$ resolution has been used extensively with previous studies conducted with RegCM and thus provides a link between our results and other RegCM studies [e.g., Solmon et al., 2006]. All simulations are run for the years 1996-2008, with analysis focused on years 1997-2008 to allow one year for model equilibration.

\section{Evaluation of the Effect of Emission Inventory}

\subsection{Comparison of Model and Measurements}

[16] Because our primary interest is the long-term climatic impact of aerosols and not the ability to replicate specific pollution episodes, we evaluate summer (June-July-August; JJA) and winter (December-January-February; DJF) climatological averages (1997-2008) for the EP and ED $25 \mathrm{~km}$ simulations. We evaluate model performance using data from three sampling networks across the continental U.S.: (1) the U.S. EPA's Clean Air Status and Trends Network (CASTNET) for $\mathrm{SO}_{2}$ and $\mathrm{SO}_{4}^{2-}$, (2) the U.S. Interagency 


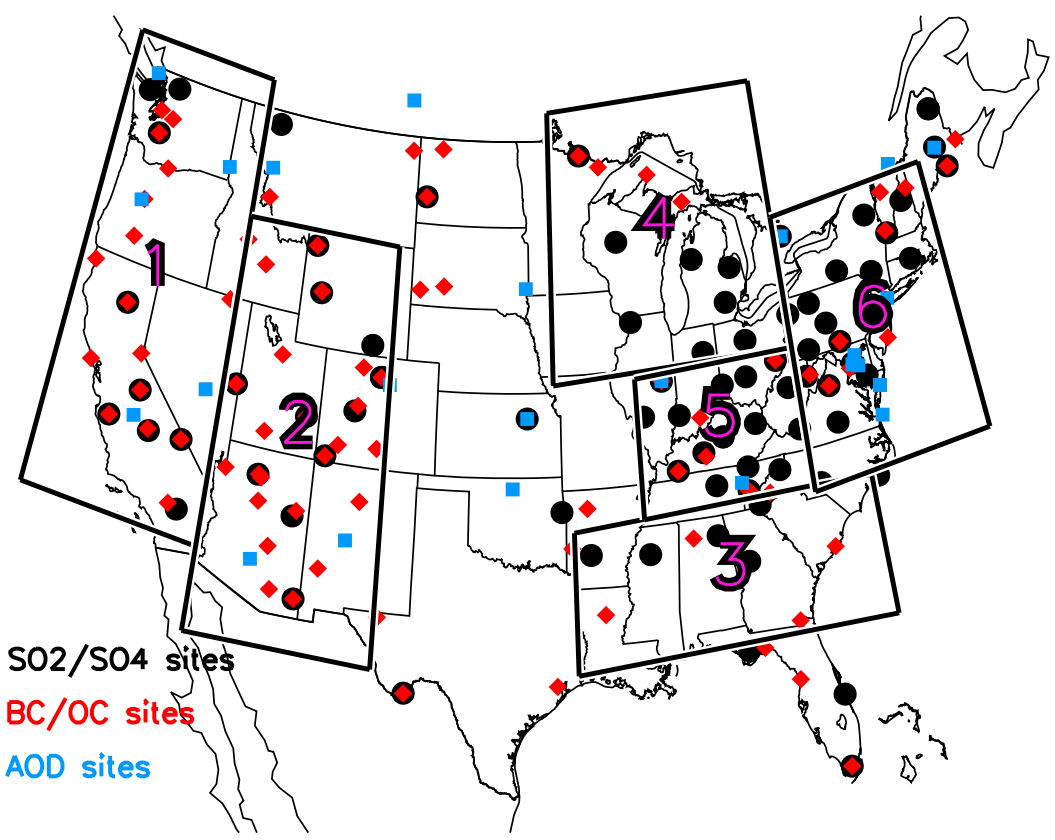

Figure 2. Location of the CASTNET $\mathrm{SO}_{2} / \mathrm{SO}_{4}^{2-}$ (black circles), IMPROVE black carbon (BC) and organic carbon (OC; red diamonds), and AERONET aerosol optical depth (AOD) (blue squares) measurement sites.

Monitoring of Protected Visual Environments (IMPROVE) network for $\mathrm{BC}$ and $\mathrm{OC}$, and (3) the AErosol RObotic NETwork (AERONET) for AOD (locations in Figure 2). Sites with less than 7 years of surface concentration measurements were not included in the analysis, which ensures that the measurement record covers more than half of the simulation. Due to the limited number of sites meeting this criterion for the AERONET sites, a minimum of 5 years of data was used for the AOD data. Domain-wide linear regressions use the monthly mean of the measurement and model data during 1997-2008 as the independent and dependent variables, respectively. Regional regressions use only the data that falls within the regions identified in Figure 2 to identify various regional emission sources and climate impacts. Regression slopes were evaluated for statistical significance using a student's t-test, and all domainwide regressions and approximately half the regional regressions were found to be significant. Regional regressions without a slope significantly different than zero are not reported. Regions absent from Tables 3-5 indicate that the regional regression slopes were not significantly different from zero.

\subsection{1. $\mathrm{SO}_{2}$ and $\mathrm{SO}_{4}^{2-}$}

[17] Surface measurements from the CASTNET air monitoring network are compared to simulated monthly averaged $\mathrm{SO}_{2}$ and $\mathrm{SO}_{4}^{2-}$ for model evaluation. CASTNET data are available as 7-day averages, which were further averaged to monthly values for this comparison. Data from 85 sites were used for the comparison (black circles in Figure 2), which are primarily located in the northeastern portion of the U.S., the region with the highest emissions. The measurement data show distinct seasonal patterns, with the $\mathrm{SO}_{2}$ higher in DJF (mean of 7.72 and a maximum of 25$30 \mathrm{ppbm}$ ) relative to JJA (mean of 6.12 and a maximum of $12 \mathrm{ppbm})$. The mean $\mathrm{SO}_{4}^{2-}$ is also higher in DJF $(2.08$ ppbm) relative to JJA $(1.30 \mathrm{ppbm})$, but the range of $\mathrm{SO}_{4}^{2-}$ is much higher in JJA (12-14 ppbm) than in DJF (5 ppbm). This cycle reflects increased $\mathrm{SO}_{2}$-to- $\mathrm{SO}_{4}^{2-}$ conversion in JJA relative to DJF, but with more removal of both species in JJA. This follows other published studies of the seasonal

Table 3. Summary of Domain-Averaged Surface Concentrations and Slope and Correlation Coefficients ( $r$, in Parentheses) From Domain-Wide and Regional Linear Regressions Between Measurements and Modeled Surface $\mathrm{SO}_{x}$ Concentrations ${ }^{\mathrm{a}}$

\begin{tabular}{|c|c|c|c|c|c|c|c|}
\hline Species and Season & $\begin{array}{l}\text { Mean Surface } \\
\text { Concentration }\end{array}$ & Domain & Region 1 & Region 3 & Region 4 & Region 5 & Region 6 \\
\hline $\mathrm{SO}_{2} \mathrm{EP} \mathrm{DJF}$ & 8.423 & $1.16(0.82)$ & $1.01(0.62)$ & $1.15(0.86)$ & $0.96(0.78)$ & $0.59(0.55)$ & $0.93(0.64)$ \\
\hline $\mathrm{SO}_{2}$ EP JJA & 6.665 & $2.06(0.74)$ & $0.03(0.05)$ & $1.74(0.83)$ & $1.76(0.81)$ & $0.55(0.28)$ & $1.69(0.61)$ \\
\hline $\mathrm{SO}_{4}^{2-} \mathrm{EP}$ DJF & 2.381 & $0.90(0.64)$ & $0.06(0.16)$ & $0.33(0.40)$ & $0.11(0.20)$ & $0.78(0.44)$ & $0.98(0.43)$ \\
\hline $\mathrm{SO}_{4}^{2-} \mathrm{EP} \mathrm{JJA}$ & 1.375 & $0.11(0.48)$ & $0.00(0.00)$ & $0.08(0.43)$ & $0.19(0.75)$ & $0.19(0.42)$ & $0.25(0.63)$ \\
\hline $\mathrm{SO}_{2} \mathrm{ED} \mathrm{DJF}$ & 9.589 & $0.83(0.78)$ & $1.79(0.50)$ & $1.06(0.81)$ & $0.84(0.70)$ & $0.59(0.65)$ & $0.52(0.49)$ \\
\hline $\mathrm{SO}_{2} \mathrm{ED} J J A$ & 7.844 & $1.54(0.72)$ & $-0.11(-0.09)$ & $1.74(0.73)$ & $1.53(0.68)$ & $0.74(0.48)$ & $1.02(0.47)$ \\
\hline $\mathrm{SO}_{4}^{2-} \mathrm{ED} \mathrm{DJF}$ & 2.522 & $0.63(0.65)$ & $0.09(0.21)$ & $0.22(0.40)$ & $0.09(0.20)$ & $0.61(0.54)$ & $0.41(0.35)$ \\
\hline $\mathrm{SO}_{4}^{2-}$ ED JJA & 1.774 & $0.08(0.47)$ & $0.00(0.02)$ & $0.06(0.39)$ & $0.15(0.72)$ & $0.13(0.47)$ & $0.13(0.46)$ \\
\hline
\end{tabular}

\footnotetext{
${ }^{a}$ Regressions that are significantly different than zero are in bold font.
} 
Table 4. Summary of Domain-Averaged Surface Concentrations and Slope and Correlation Coefficients ( $r$, in Parentheses) From Domain-Wide and Regional Linear Regressions Between Measurements and Modeled Surface Black and Organic Carbon Concentrations ${ }^{\mathrm{a}}$

\begin{tabular}{|c|c|c|c|c|c|c|c|}
\hline Species and Season & $\begin{array}{l}\text { Mean Surface } \\
\text { Concentration }\end{array}$ & Domain & Region 1 & Region 3 & Region 4 & Region 5 & Region 6 \\
\hline BC EP DJF & 0.191 & $0.42(0.56)$ & $0.08(0.26)$ & $-0.01(-0.05)$ & $0.43(0.44)$ & $0.55(0.61)$ & $0.34(0.69)$ \\
\hline BC EP JJA & 0.163 & $0.22(0.43)$ & $-0.01(-0.04)$ & $0.26(0.68)$ & $0.04(0.19)$ & $0.41(0.60)$ & $0.32(0.70)$ \\
\hline BC ED DJF & 0.211 & $0.28(0.59)$ & $0.09(0.42)$ & $-0.01(-0.07)$ & $0.32(0.44)$ & $0.18(0.49)$ & $0.27(0.72)$ \\
\hline BC ED JJA & 0.174 & $0.15(0.44)$ & $0.01(0.06)$ & $0.09(0.56)$ & $0.04(0.22)$ & $0.11(0.52)$ & $0.26(0.72)$ \\
\hline OC EP DJF & 0.418 & $0.23(0.53)$ & $0.02(0.08)$ & $-0.03(-0.17)$ & $0.16(0.33)$ & $0.18(0.33)$ & $0.20(0.66)$ \\
\hline OC EP JJA & 0.358 & $0.02(0.15)$ & $-0.01(-0.07)$ & $0.07(0.42)$ & $0.00(0.00)$ & $-0.03(-0.10)$ & $0.07(0.36)$ \\
\hline OC ED DJF & 0.458 & $0.16(0.52)$ & $0.05(0.23)$ & $-0.01(-0.06)$ & $0.07(0.24)$ & $0.06(0.28)$ & $0.14(0.52)$ \\
\hline OC ED JJA & 0.381 & $0.01(0.12)$ & $-0.00(-0.08)$ & $0.01(0.14)$ & $0.00(-0.05)$ & $0.00(-0.05)$ & $0.05(0.30)$ \\
\hline
\end{tabular}

${ }^{\mathrm{a}}$ Regressions that are significantly different than zero are in bold font.

cycle of $\mathrm{SO}_{4}^{2-}$, with greater concentrations in summer than winter over most of the United States [Malm et al., 2004; Jaffe et al., 2005; Luo et al., 2011].

[18] In DJF, the EP simulation captures the general spatial pattern of $\mathrm{SO}_{2}$ and $\mathrm{SO}_{4}^{2-}$, with relatively high concentrations in the eastern portion of the U.S. and relatively low concentrations in the western U.S. (Figures $3 \mathrm{a}$ and $3 \mathrm{c}$ and Figures $4 \mathrm{a}$ and $4 \mathrm{c})$. The modeled $\mathrm{SO}_{2}$ is biased slightly high $(16 \%)$ relative to the measurements with concentrations centered around the regression line, while the modeled $\mathrm{SO}_{4}^{2-}$ is biased slightly low (10\%, Table 3$)$. In JJA, however, the EP simulation fails to reproduce the observed concentrations, where $\mathrm{SO}_{2}$ is overestimated by $106 \%$. While the statistical mean EP $\mathrm{SO}_{2}$ is similar to the statistical mean measured concentrations, maximum simulated $\mathrm{SO}_{2}$ concentrations are more than three times higher than the maximum measured concentrations. In contrast to the $\mathrm{SO}_{2}$, the $\mathrm{SO}_{4}^{2-}$ is underestimated by $90 \%$. Similar to $\mathrm{SO}_{2}$, mean concentrations are similar but the maximum modeled $\mathrm{SO}_{4}^{2-}$ is a factor of 2.5 lower than the maximum measured $\mathrm{SO}_{4}^{2-}$. These biases also suggest incomplete conversion of $\mathrm{SO}_{2}$ to sulfate in the model, as noted in other RegCM studies [e.g., Solmon et al., 2006] where it was attributed to an underestimate of the gaseous conversion by $\mathrm{OH}$ and the lack of aqueous production via O3 reduction. Despite the differences in $\mathrm{SO}_{2}$ emissions between the EPA and EDGAR inventories, the ED simulation of $\mathrm{SO}_{2}$ and $\mathrm{SO}_{4}^{2-}$ is quite similar to the EP simulation. As with EP, the DJF ED simulation compares well with observations, and are $17 \%$ lower for $\mathrm{SO}_{2}$ and $37 \%$ lower than observed for $\mathrm{SO}_{4}^{2-}$. In JJA, the same pattern of high $\mathrm{SO}_{2}$ and low $\mathrm{SO}_{4}^{2-}$ is present in the ED simulation, again suggesting the incomplete chemical conversion of $\mathrm{SO}_{2}$ to $\mathrm{SO}_{4}^{2-}$.

[19] The seasonal changes in the model sulfate biases (e. g., stronger biases in JJA than DJF and the consistent overestimation of $\mathrm{SO}_{2}$ and underestimation of $\mathrm{SO}_{4}^{2-}$ ) suggests incomplete chemical conversion in the model, as noted above. To explore the sulfate conversion, the total sulfur contributed by each species (Figures $5 \mathrm{a}$ and $5 \mathrm{~b}$ ) and the ratio of $\mathrm{SO}_{2}$ to $\mathrm{SO}_{4}^{2-}$ (not shown) were also examined. The regression of modeled versus the measured total sulfur are remarkably similar in both seasons, with the ED low by 10 $17 \%$ and the EP high by $15-22 \%$, reflecting the DJF regressions for $\mathrm{SO}_{2}$ and the nature of high-resolution point sources in the EP inventory. These results support the conclusion that the emission inventories capture the $\mathrm{SO}_{2}$ emissions fairly well. The comparison of modeled and measured $\mathrm{SO}_{2} / \mathrm{SO}_{4}^{2-}$ ratios, however, are starkly different in each season and show that the ratio of $\mathrm{SO}_{2} / \mathrm{SO}_{4}^{2-}$ is much higher than it should be in JJA. These observations support the hypothesis that the sulfate conversion likely contributes to the JJA model bias.

[20] An examination of the domain-averaged column profiles for $\mathrm{SO}_{2}$ and $\mathrm{SO}_{4}^{2-}$ shows that vertical mixing could also play a role in the surface model biases. Vertical profiles show higher concentrations aloft (greater than 0.9 sigma, approximately $870 \mathrm{mb}$ ) in JJA than DJF, suggesting an increase in summer vertical mixing (Figures $6 \mathrm{a}$ and $6 \mathrm{~b}$ ). Surface $\mathrm{SO}_{2}$ and $\mathrm{SO}_{4}^{2-}$ concentrations are greater in DJF than JJA for both ED and EP simulations, and as noted above, are close in magnitude despite the ED emissions being approximately $20 \%$ higher. However, ED concentrations of sulfate are higher than EP aloft particularly in the summer, reflecting the increased ED emission inventory. This behavior suggests that part of the model bias could be due to the excessive vertical mixing in the model, which could reduce surface concentrations through strong mixing.

[21] Finally, the vertical profile and sulfate column burden is also important for understanding the climate effects of sulfate. The domain-average total $\mathrm{SO}_{4}^{2-}$ column burden (Figure 7a) shows a strong seasonal cycle and peaks in August and September. Total column sulfate production outweighs removal throughout the year, leading to an increase in net sulfate production in the early summer and an increase in column burden in late summer. However, due to the increase in vertical mixing and higher winds aloft, there

Table 5. Summary of Domain-Averaged Aerosol Optical Depth (AOD) and Slope and Correlation Coefficients ( $r$, in Parentheses) From Domain-Wide and Regional Linear Regressions Between Measurements and Modeled AOD ${ }^{\mathrm{a}}$

\begin{tabular}{lccccc}
\hline Species and Season & Mean AOD & Domain & Region 1 & Region 5 & Region 6 \\
\hline AOD EP DJF & 0.114 & $\mathbf{0 . 6 8 ( 0 . 2 6 )}$ & $-0.08(-0.34)$ & $0.28(0.09)$ & $0.05(0.02)$ \\
AOD EP JJA & 0.084 & $\mathbf{0 . 3 1}(\mathbf{0 . 7 4 )}$ & $0.02(0.09)$ & $0.14(0.45)$ & $\mathbf{0 . 1 7}(\mathbf{0 . 4 7 )}$ \\
AOD ED DJF & 0.149 & $\mathbf{0 . 4 8}(\mathbf{0 . 2 0})$ & $-0.18(-0.30)$ & $0.39(0.14)$ & $-0.01(0.00$ \\
AOD ED JJA & 0.103 & $\mathbf{0 . 2 4}(\mathbf{0 . 7 0 )}$ & $-0.06(-0.08)$ & $0.10(0.38)$ & $\mathbf{0 . 1 8}(\mathbf{0 . 5 7})$ \\
\hline
\end{tabular}

\footnotetext{
${ }^{\mathrm{a}}$ Regressions that are significantly different than zero are in bold font. Note: No AOD measurement sites were available for regions 3 and 4.
} 

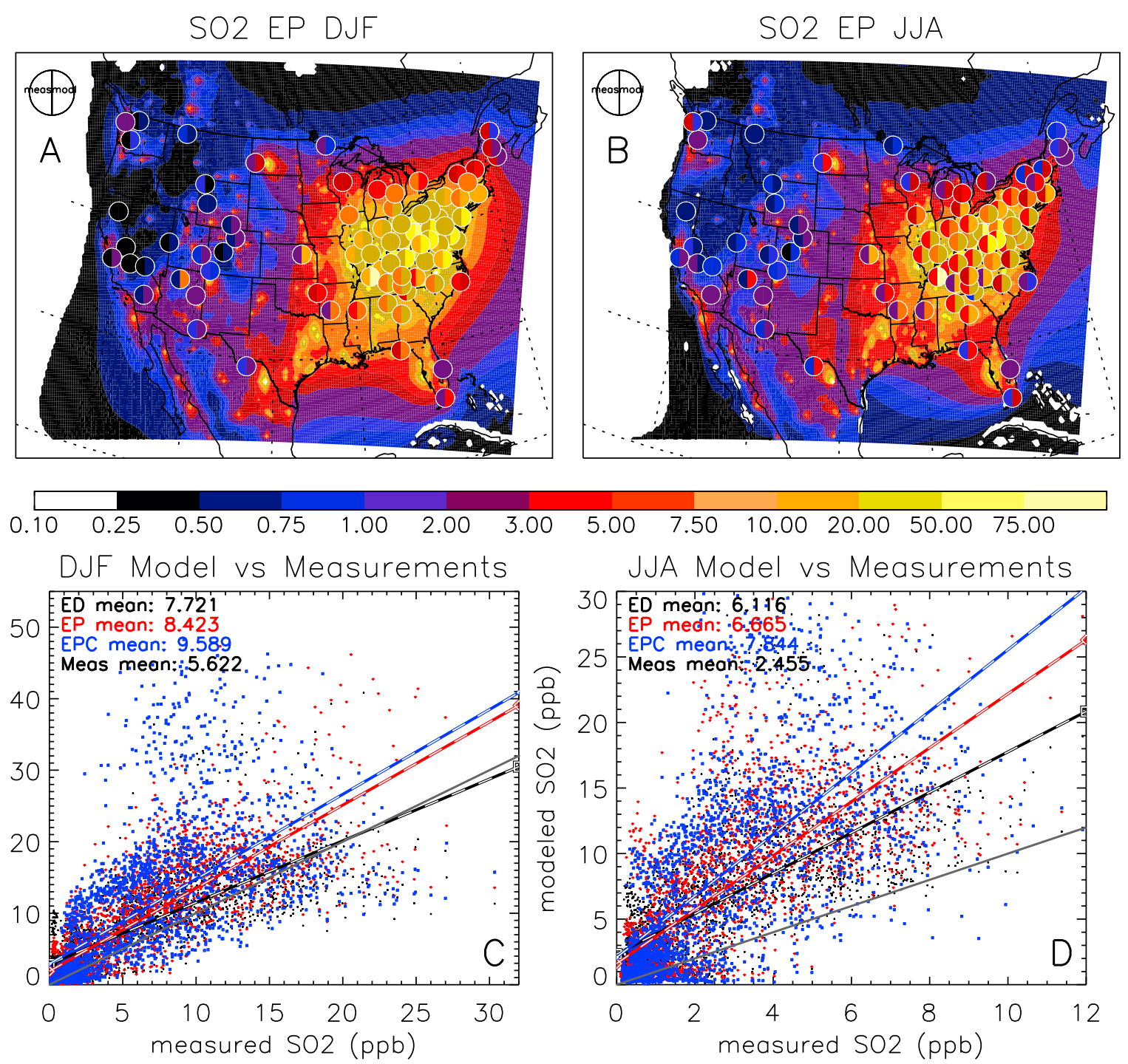

Figure 3. Contours of climatological modeled $\mathrm{SO}_{2}$ concentrations for (a) DJF and (b) JJA for the EPA $25 \mathrm{~km}$ simulation (EP). CASTNET ground-based measurement locations are indicated with circles colored by the measured mean concentrations (right half) and corresponding modeled concentrations (left half). Monthly measured/modeled data and regression lines for the EDGAR $25 \mathrm{~km}$ (black), EP (red), and EPA 60-km (blue) simulations are shown for (c) DJF and (d) JJA. The 1:1 line is shown in dot-dashed gray.

is a greater flux out of the model domain in the summertime, leading to a lag in the modeled column burden. In our simulations, the gaseous conversion increases in the summer, but is an order of magnitude less than the aqueous conversion (not shown). While this lack of conversion could create the low JJA SO ${ }_{4}^{2-}$, it is likely that the increased vertical transport decreases the modeled surface $\mathrm{SO}_{4}^{2-}$ as well. The vertical transport and impact on wet removal is discussed further in section 4 .

[22] The sensitivity of the model to $\mathrm{SO}_{2}-\mathrm{SO}_{4}^{2-}$ conversion and transport parameterizations has been tested in other RegCM studies [Qian et al., 2001; Solmon et al., 2006]. Qian et al. [2001] found that sulfate concentrations were predominantly sensitive to emission sources, aqueous conversion and wet removal, with little sensitivity to gas phase conversion and dry deposition. However, the lack of comparison to measured sulfate in this paper does not provide any quantitative information about the sulfate formation in these simulations over East Asia. Solmon et al. [2006] tested the sensitivity of aerosol aging, emission strength, and convective transport over northern Africa and Europe, finding that found increased convective mixing decreased the surface concentrations of $\mathrm{SO}_{4}^{2-}$ from $5-40 \%$ in JJA. Based on these previous studies and the results found here, the implication is that the vertical transport can be an important driver in surface concentration evaluations. Additionally, our degraded evaluations in summertime compared to winter suggest that vertical mixing could definitely affect model biases. However, the relative overestimate of summer $\mathrm{SO}_{2}$ and underestimate of $\mathrm{SO}_{4}^{2-}$ points to insufficient conversion from $\mathrm{SO}_{2}$ to $\mathrm{SO}_{4}^{2-}$. 

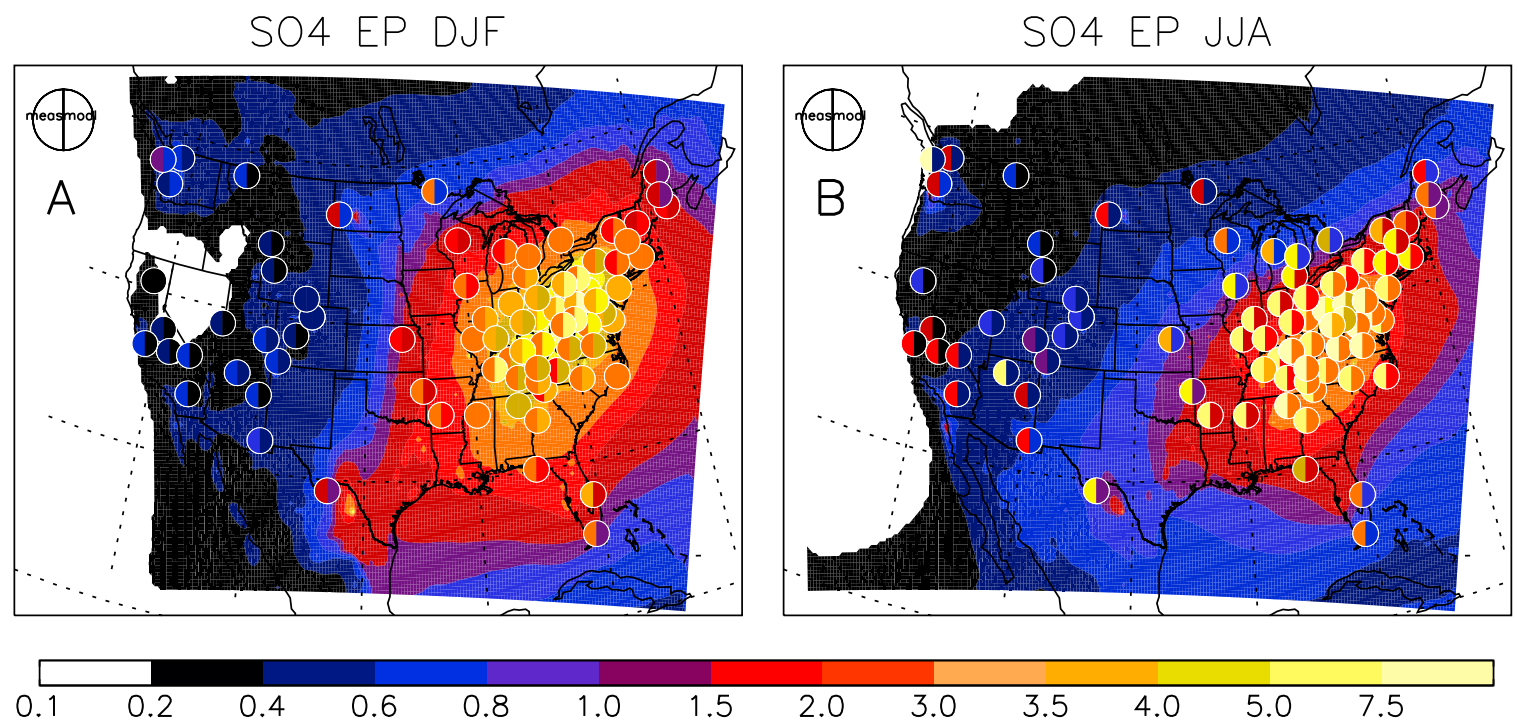

\section{DJF Model vs Measurements}
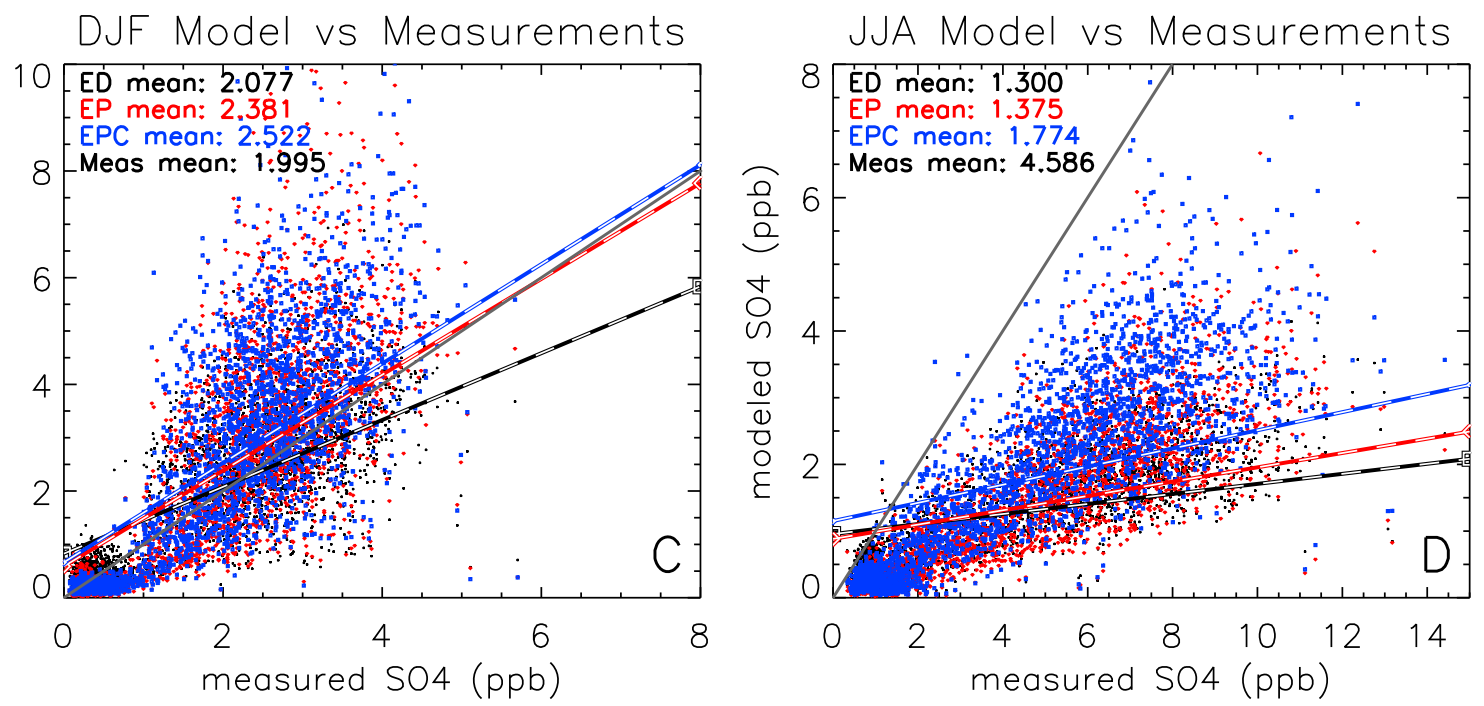

Figure 4. Same as Figure 3, but for $\mathrm{SO}_{4}^{2-}$.

DJF Model vs Measurements

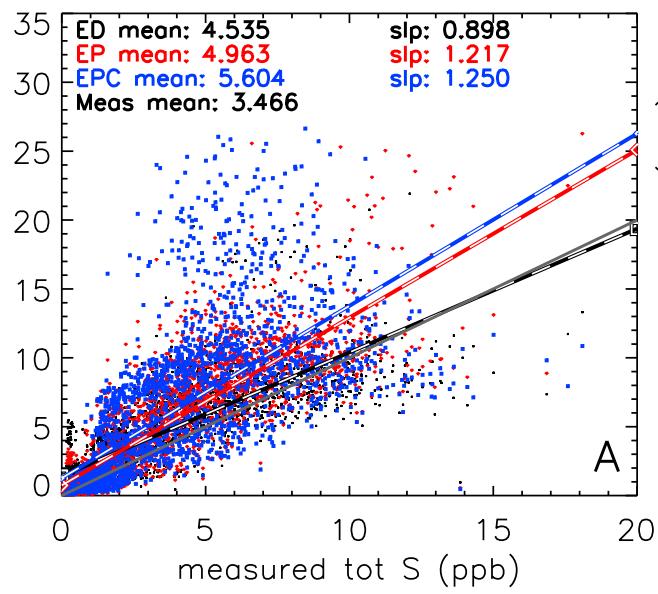

JJA Model vs Measurements

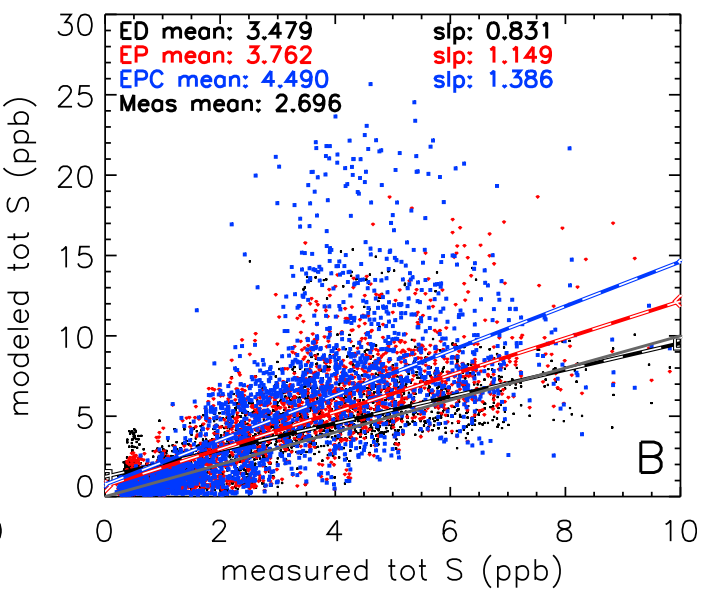

Figure 5. Monthly measured/modeled data and regression lines of the total sulfur for the EDGAR $25 \mathrm{~km}$ (black), EP (red), and EPA 60-km (blue) simulations are shown for (a) DJF and (b) JJA. The 1:1 line is shown in dot-dashed gray. 

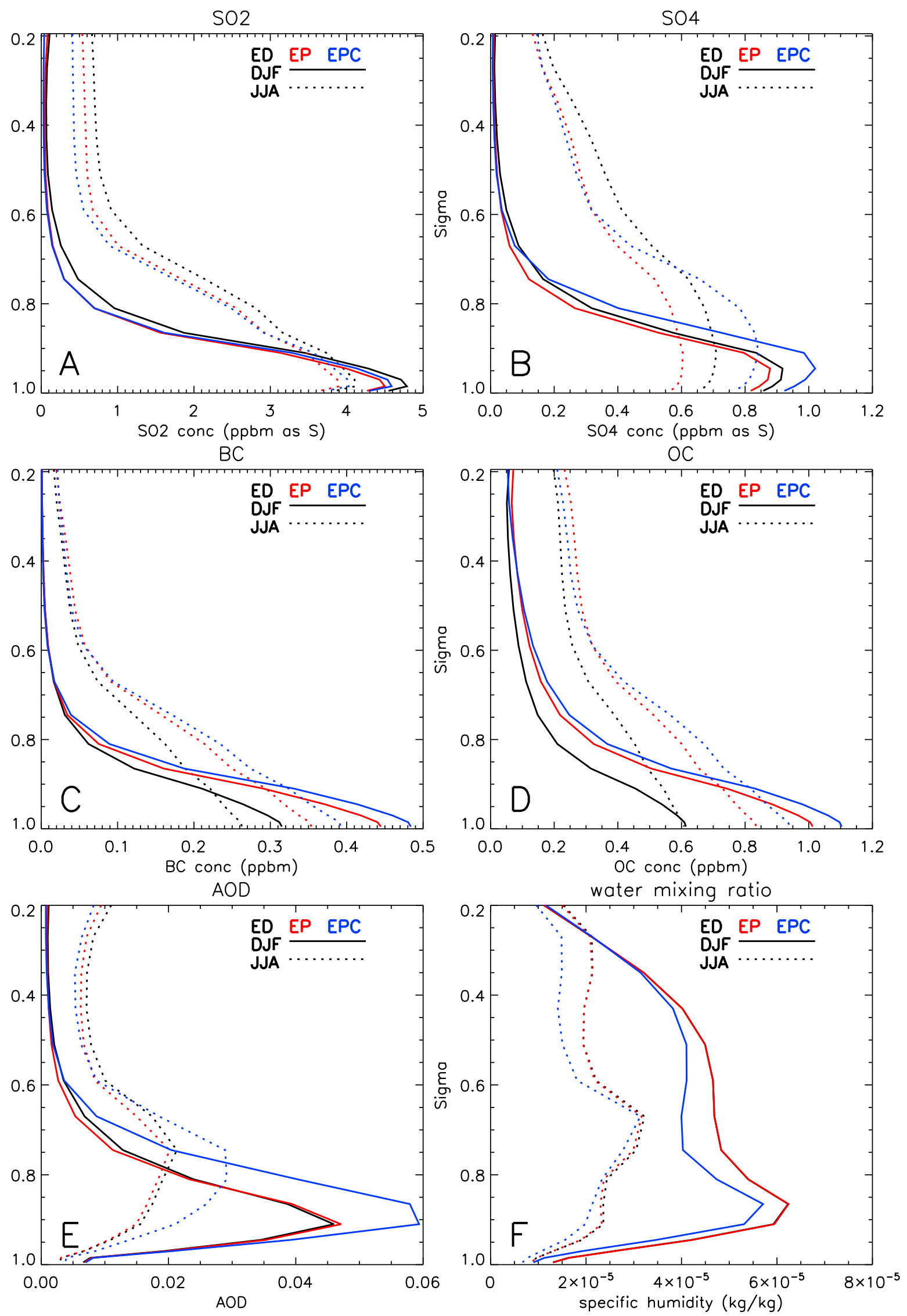

Figure 6. Domain-average vertical profiles of concentrations of (a) $\mathrm{SO}_{2}$, (b) $\mathrm{SO}_{4}^{2-}$, (c) black carbon (BC), (d) organic carbon (OC), (e) aerosol optical depth (AOD), and (f) the specific humidity. 

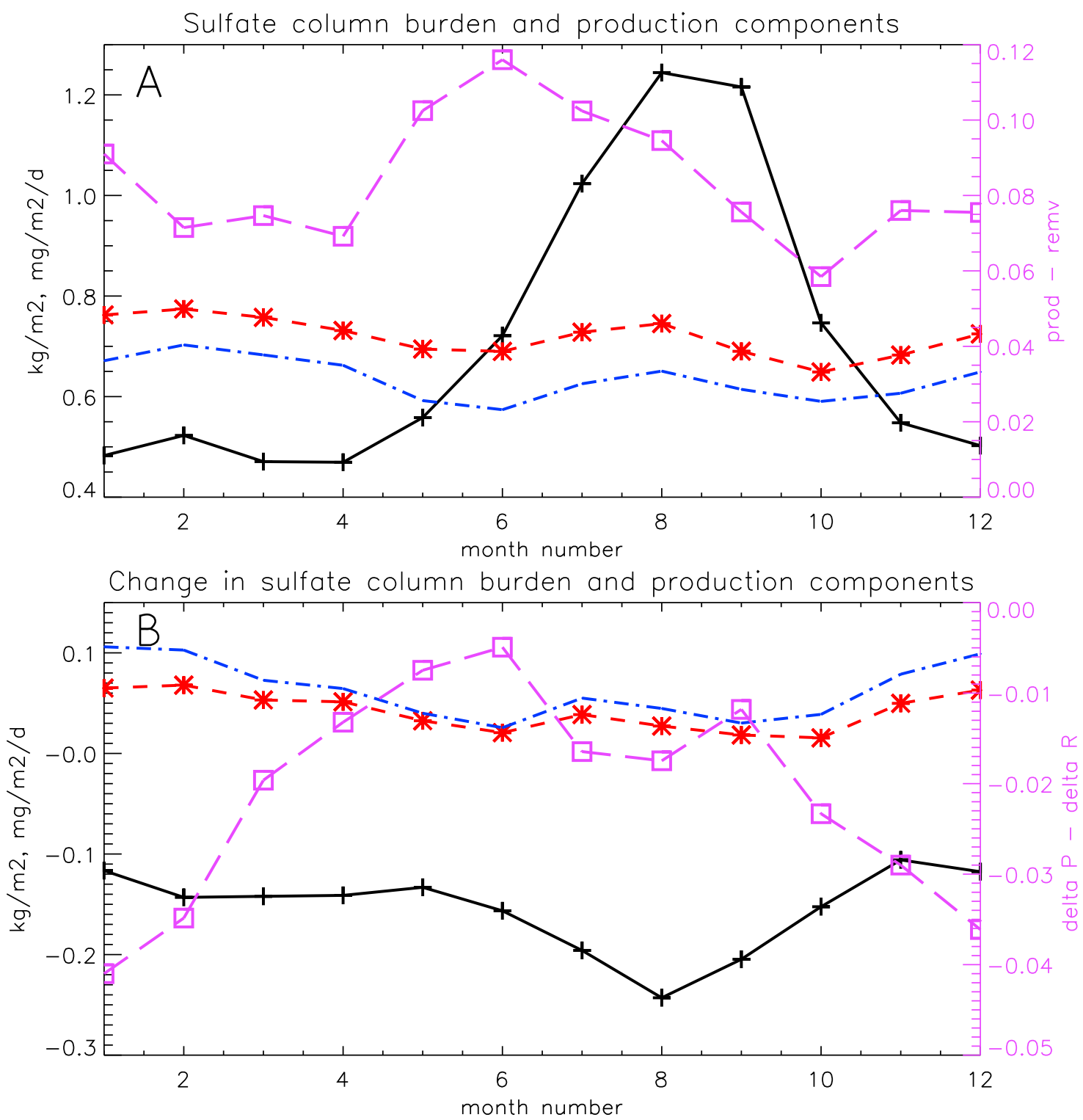

Figure 7. (a) Seasonal, domain-wide average of the $\mathrm{SO}_{4}^{2-}$ column burden (black; $\mathrm{kg} / \mathrm{m}^{2}$ ), total $\mathrm{SO}_{4}^{2-}$ production rate $\left(\mathrm{red} ; \mathrm{kg} / \mathrm{m}^{2} / \mathrm{d}\right.$ ), total $\mathrm{SO}_{4}^{2-}$ removal rate (blue; $\mathrm{kg} / \mathrm{m}^{2} / \mathrm{d}$ ), and difference between the production and removal (magenta) for $\mathrm{SO}_{4}^{2-}$ from the EPA $25 \mathrm{~km}$ simulation (EP) simulation, and (b) the difference between the EP and EPA $60 \mathrm{~km}$ simulation (EPC)C simulation for the corresponding components of the $\mathrm{SO}_{4}^{2-}$ budget.

[23] In summary, the JJA under-prediction of sulfate could be due to two processes: (1) errors in the chemical conversion of sulfate and (2) a strong vertical mixing component that decreases surface concentrations in comparison to observations. Further evaluation will be required to isolate these processes, including estimates of turbulent mixing from surface flux sites or vertical profiles of speciated aerosols. These parameterizations and potential improvements will be further explored in additional modeling simulations.

\subsubsection{Evaluation of Black and Organic Carbon (BC and $\mathrm{OC}$ )}

[24] Surface measurements from the IMPROVE air monitoring network are compared to simulated monthly averaged total $\mathrm{BC}\left(\mathrm{BC}_{h b}+\mathrm{BC}_{h l}\right)$ (Figure 8$)$ and total $\mathrm{OC}\left(\mathrm{OC}_{h b}\right.$
$+\mathrm{OC}_{h l}$ ) (not shown). IMPROVE data from 79 sites (Figure 2) are available as 3-day averages, which were further averaged to monthly values for this comparison. IMPROVE sites are located in National Parks, which biases sites towards rural regions concentrated in the western U.S. with relatively sparse coverage in the central and eastern U.S. Only sites containing both $\mathrm{BC}$ and $\mathrm{OC}$ measurements were used. While both $\mathrm{BC}$ and $\mathrm{OC}$ are missing significant biogenic sources [e.g., Jimenez et al., 2009], both are relevant to the discussion in the following sections and provide a constraint upon the role of anthropogenic carbonaceous aerosols in climate over the U.S.

[25] In DJF, the EP simulation underestimates BC and OC by $58 \%$ and $77 \%$ (domain average), respectively, and neither is well correlated with observations (Figures $8 \mathrm{a}$ and $8 \mathrm{c}$ and 

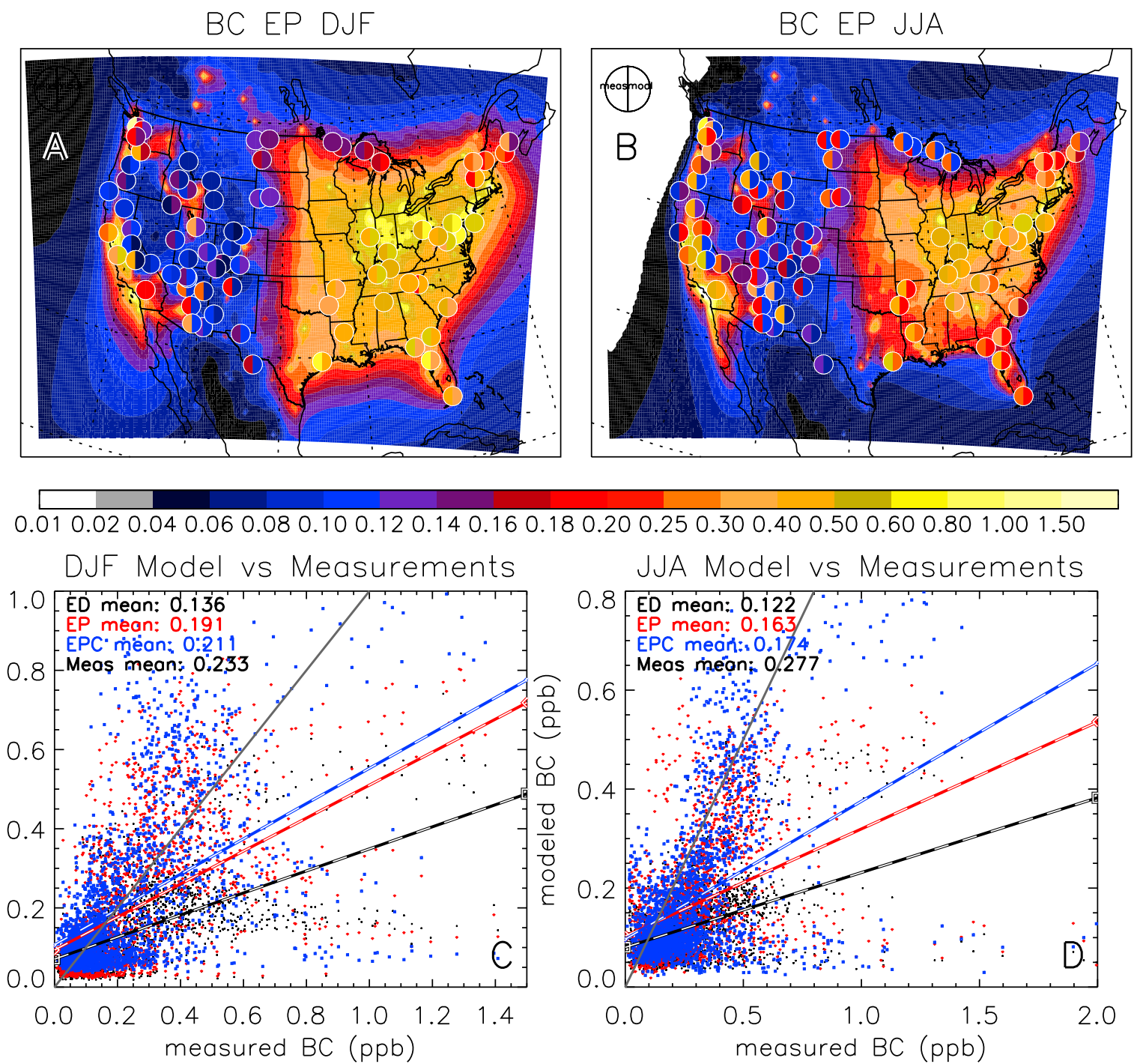

Figure 8. Same as Figure 3, but for black carbon $(\mathrm{BC})$ using measurement data from the IMPROVE network.

Table 4). In JJA, the correlation between the model and measurements degrades significantly, particularly for OC, where there appears to be little correlation between the modeled and measured OC in JJA, which is likely caused by the lack of biogenic organic aerosol in our model. For BC, observations during both seasons show likely biomass burning events which produce a broad range of $\mathrm{BC}$ concentrations (up to $2-3 \mathrm{ppbm}$ ) that are not matched in the model (simulated values typically peak at $0.5 \mathrm{ppbm}$ ).

[26] As in the EP simulation, the ED BC and OC concentrations are also underestimated by the model in both seasons. Again, the $\mathrm{BC}$ results are slightly skewed by the apparent absence of biomass burning events in the western U.S., leading to reduced measured-modeled agreement. Regional results are consistent with the domain-wide results, with the exception of region 6 , which maintains similar slope and fit values from DJF to JJA. The modeled OC in JJA is similarly uncorrelated to measurements by an an apparent lack of biogenic emissions.

[27] For the carbonaceous aerosols, the EP inventory results in the best measured-modeled agreement in both seasons. It is important to note that the EP inventory only includes emissions from fossil fuel combustion, therefore an increase in agreement reflects the anthropogenic emissions inventory component only. Interestingly, the surface concentrations of both $\mathrm{BC}$ and $\mathrm{OC}$ are significantly higher in the EP simulations (33-40\%). However, at higher altitudes, however, the two inventories are virtually identical when comparing within a season. As noted in the sulfur comparison, the profiles indicate greater vertical mixing in JJA, which is likely a contributing factor to the decrease in modeled surface concentrations from DJF to JJA.

[28] As with sulfur species, DJF represents a time period when the simplified model parameterizations most accurately mimic reality, despite comparison statistics that suggest missing or underestimated sources. We conducted two additional sensitivity tests of the effect of emission strength, which increased BC emissions by a factor of 2.25 and OC emissions by a factor of 4.4 (the inverse of the slope for the EPC DJF regression) for a $60 \mathrm{~km}$ resolution simulation. The increased emissions substantially increased the simulated $\mathrm{BC}$ and $\mathrm{OC}$, however, the $r$ was virtually unchanged. The 

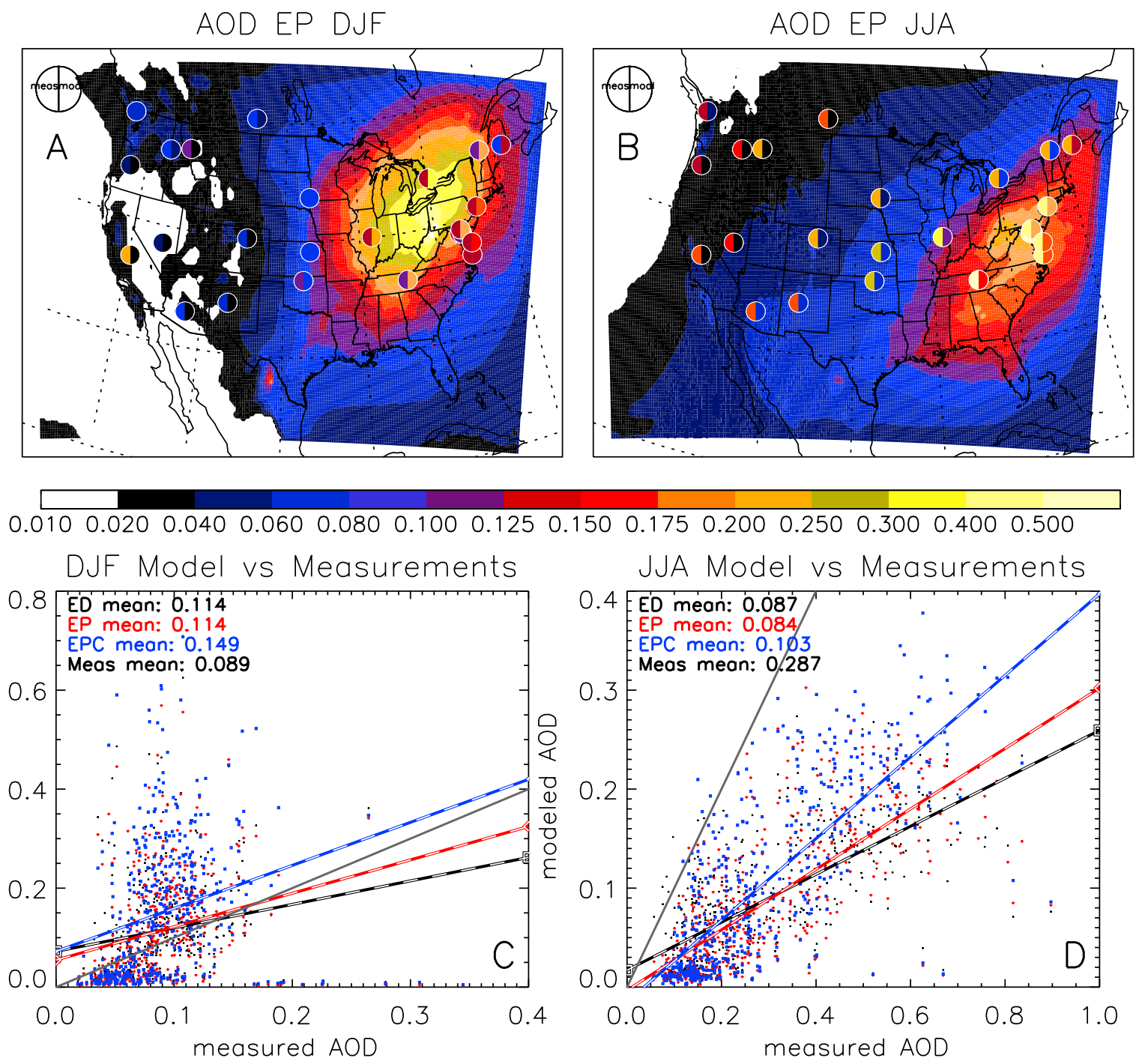

JJA Model vs Measurements

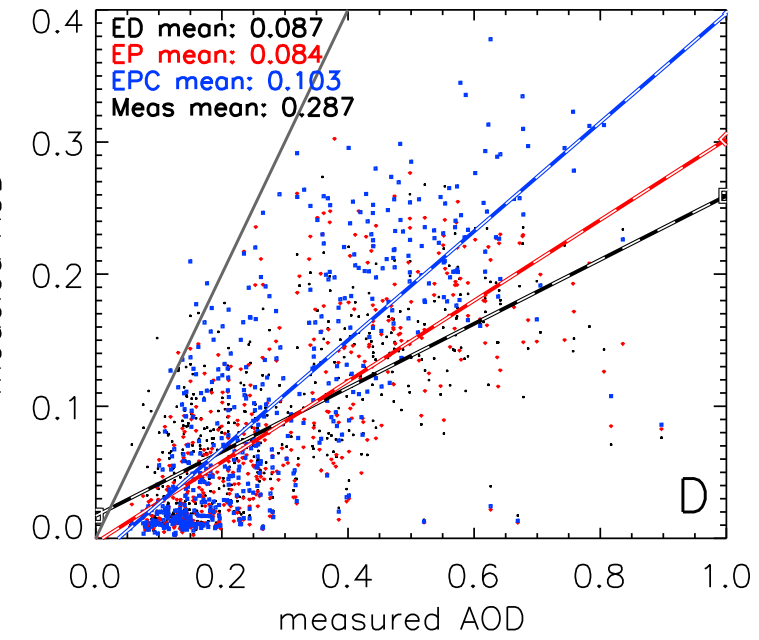

Figure 9. Same as Figure 3, but for aerosol optical depth (AOD) using measurement data from the AERONET network.

modeled values remained poorly correlated with the measurements, strongly suggesting that missing carbonaceous sources are likely to be the cause of the measured-modeled discrepancies (i.e., biomass burning and biogenic emissions). Additionally, the dynamic range of the measured and modeled BC also suggests that some point sources are also missing from current anthropogenic inventories, as noted by Fernandes et al. [2007].

\subsubsection{Evaluation of Aerosol Optical Depth (AOD)}

[29] Surface measurements of AOD from AERONET, a network of ground-based sun photometers which measure atmospheric aerosol properties [Holben et al., 1998], are compared with monthly averaged simulated AOD. Here, we implement Level 2 (cloud-screened and quality assured) monthly averages from 24 sites (Figure 2). The AOD at each time step within RegCM is calculated from the aerosol concentration and extinction coefficient [Solmon et al., 2006] and modeled AOD values are representative of the mean AOD aggregated over the $350-640 \mathrm{~nm}$ spectral band. Four bands of AERONET AOD $(340,380,440$, and $500 \mathrm{~nm}$ spectral bands) were averaged to correspond to the modeled
AOD. The AOD offers a more complete evaluation of the model performance, as it incorporates all aerosols species over the whole column. However, it is inherently limited by the fact that these RegCM simulations only consider anthropogenic aerosols with notable missing sources such as biomass burning, sea salt, dust, and biogenic organics.

[30] The regression statistics show that AOD is generally underestimated in both seasons and emission scenarios. In DJF, AOD is low by $32 \%$ and $53 \%$ for EP and ED, respectively (Figures 9a and 9c). In JJA, the measured AOD roughly doubles, while the simulated EP AOD decreases by approximately half, resulting in even lower regression slopes for both emission inventories. Interestingly, however, the JJA though the $r$ is significantly improved over DJF. The low modeled JJA AOD values provides further support to missing summertime emissions and chemical conversion of sulfate in the model (noted in sections 3.1.1-3.1.2). Vertical profiles of AOD (Figure 6f) suggest that sulfate is the main driver of modeled light extinction [e.g., Ginoux et al., 2006], due to similar vertical maxima in sulfate concentration and AOD at approximately 0.9 sigma (approximately $870 \mathrm{mb}$ ). 

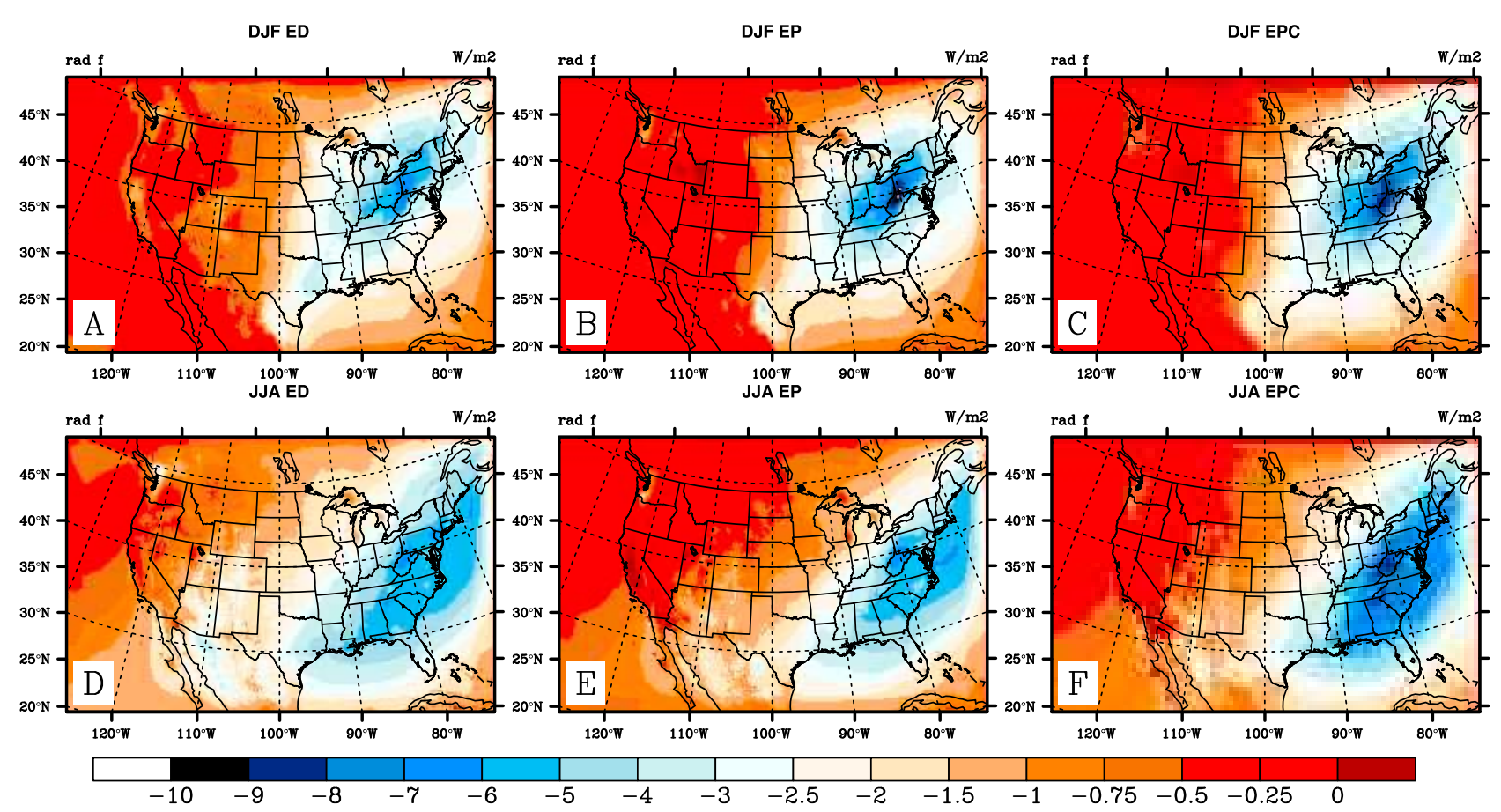

Figure 10. Spatial distribution of top of the atmosphere radiative forcing (TOA) for the EDGAR $25 \mathrm{~km}$ (ED; Figures 10a and 10d), EPA NEI $25 \mathrm{~km}$ (EP; Figures 10b and 10e), and EPA NEI $60 \mathrm{~km}$ (EPC; Figures 10c and 10f) simulations for $(a-c)$ DJF and $(d-f)$ JJA.

This supports an underestimate of JJA AOD as the sulfate species are also underestimated.

\subsection{Impact on TOA Forcing}

[31] Finally, we evaluate the direct effect of $\mathrm{SO}_{4}^{2-}, \mathrm{BC}$, and $\mathrm{OC}$ concentrations on the spatial top of the atmosphere radiative forcing (TOA), relative to clear sky conditions (Figure 10). TOA is calculated in the radiative transfer calculations as the difference in absorbed solar flux between a clear sky with no aerosols and the simulated aerosol burden. Overall, the EP and ED simulations produce similar spatial distributions with TOA slightly higher over the Ohio River Valley in the winter and the Eastern seaboard in the summer. Wintertime TOA is concentrated in the East Coast, with forcing increasing throughout the continent in the summer.
Seasonal domain-averaged TOA (Figure 11) shows that the winter forcing is almost identical between EP and ED.

[32] However, in the summer and fall, the ED TOA increases over the EP TOA by more than $1 \mathrm{Wm}^{-2}$. This is in accordance with greater $\mathrm{SO}_{2}$ emissions in the $\mathrm{ED}$ inventory and increased sulfate conversion in the summer, leading to greater sulfate concentrations throughout the vertical profile and slightly higher AOD values (Figure 6). While the atmospheric dynamics are unchanged between these two simulations, the greater concentrations in ED profile are amplified in the summer due to the increase in summertime convective mixing and summer sulfate chemical conversion. The spatial distribution of the surface radiative forcing (SRF), which is also considered in climate simulations, is nearly identical to the TOA and slightly larger in magnitude, with SRF forcings of $15 \mathrm{Wm}^{-2}\left(4-5 \mathrm{Wm}^{-2}\right.$ greater than the

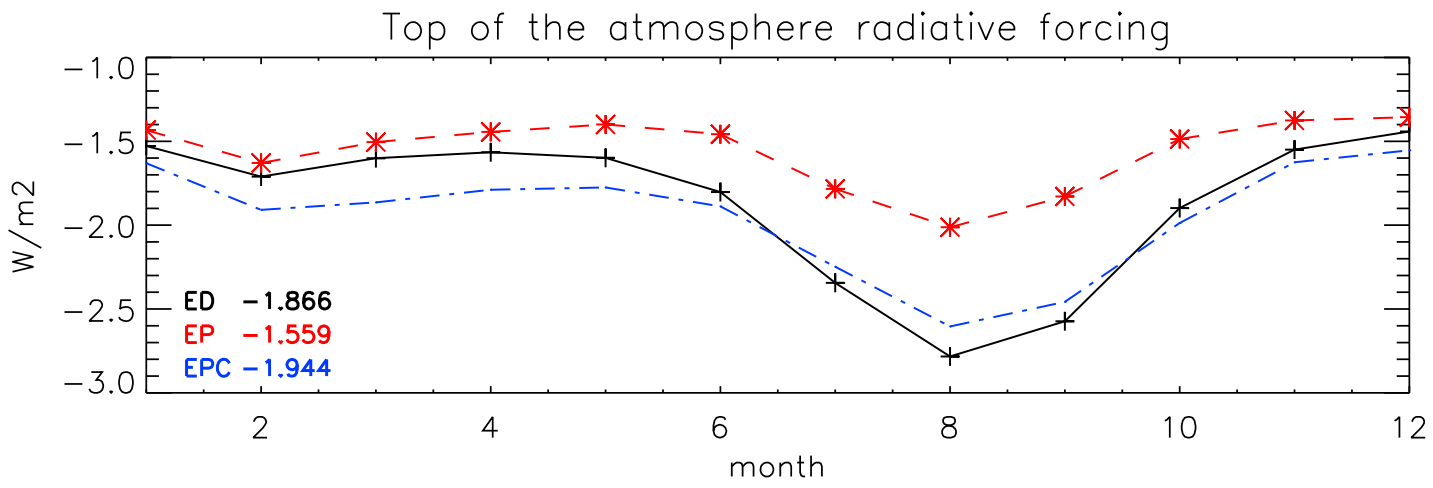

Figure 11. Domain and seasonal average of the top of the atmosphere radiative forcing (TOA) for EDGAR $25 \mathrm{~km}$ (ED; black), EPA NEI $25 \mathrm{~km}$ (EP;red), and EPA NEI $60 \mathrm{~km}$ (EPC; blue) simulations. 

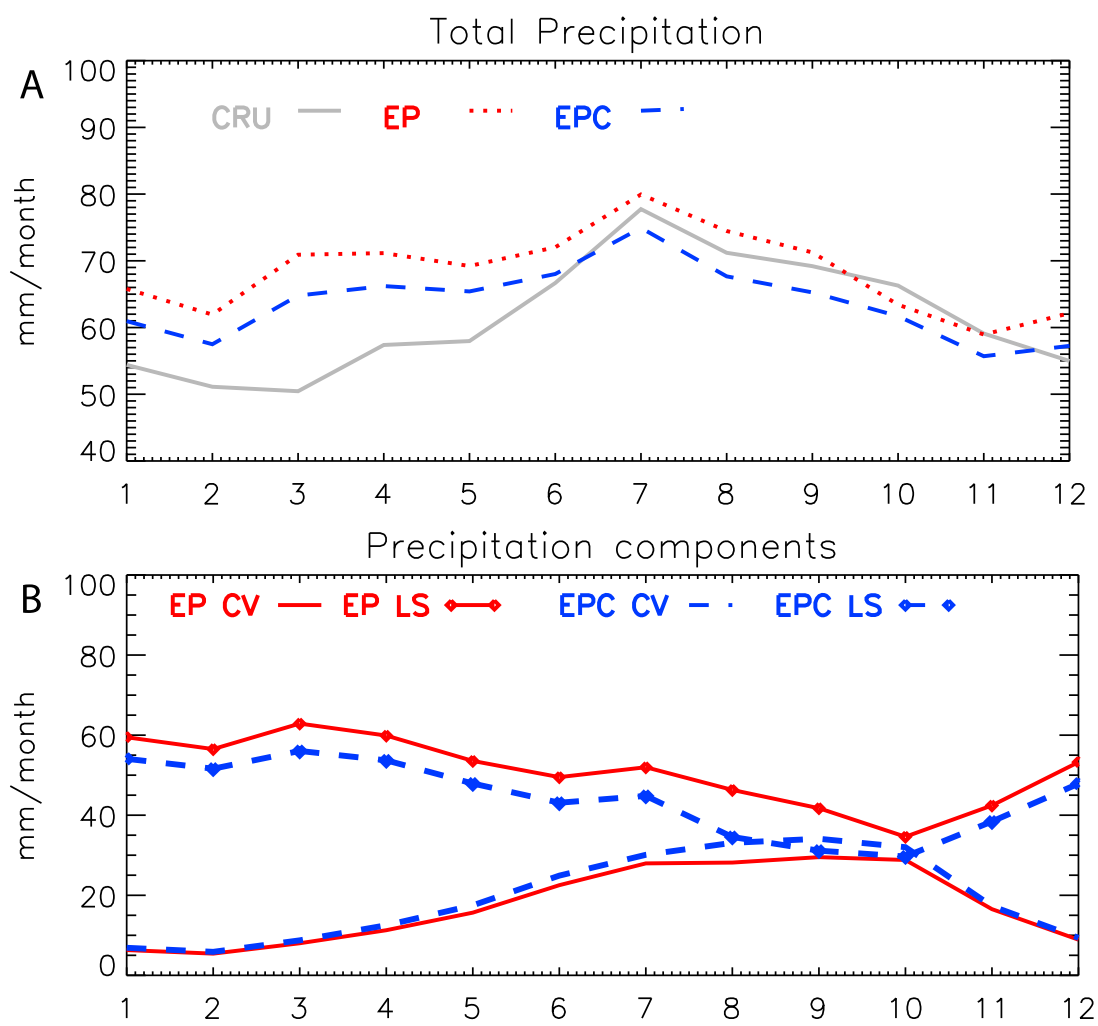

Figure 12. (a) Domain-averaged total precipitation for the observed CRU data set (black solid line), EP (red dotted line), and EPC (blue dashed line) simulations. (b) Domain-averaged convective precipitation (no symbols) and large-scale precipitation (diamonds) from EP (red) and EPC (blue) simulations.

TOA). In contrast to the analysis of species concentrations, these results suggest that the climate impact of the emissions inventory resolution can have an impact on the aerosol TOA, particularly in the summer when chemical conversion and convective mixing are more active. However, as discussed in the next section, the model resolution itself may play an equally large role at introducing uncertainty into climate model calculations.

\section{Evaluation of the Effect of Climate Model Resolution}

[33] In addition to the impact of emission inventory on precipitation and TOA, we evaluate the impact of climate model resolution by comparing the fine-scale $25 \mathrm{~km}$ resolution simulation (EP) with a coarse resolution $(60 \mathrm{~km}$; EPC) simulation using the same $4 \mathrm{~km}$ EPA emissions inventory. For individual aerosol species, the differences between the domain-wide regressions for EP and EPC were relatively small (within $7 \%$ in DJF and $28 \%$ in JJA) with slightly improved regression statistics in the EPC simulation. Despite regression similarities, EPC $\mathrm{SO}_{2}$ and $\mathrm{SO}_{4}^{2-}$ concentrations are greater than the EP in both seasons throughout the full vertical profile (e.g., Figure 6b, DJF, the mean $\mathrm{SO}_{4}^{2-}$ surface concentration increases from $0.46 \mathrm{ppbm}$ in $\mathrm{EP}$ to $0.65 \mathrm{ppbm}$ in $\mathrm{EPC}$ ). $\mathrm{BC}$ and $\mathrm{OC}$ concentrations are also higher in EPC in the lower troposphere, with greater differences in the summer than the winter. AOD is also higher in EPC, with the mean AOD increasing by 0.035 in DJF and by 0.019 in JJA. Because these two simulations are using the same emission inventories, the concentration and AOD differences are due to different physical processes in the model caused by changes in model resolution. Specific humidity profiles show that the vertical column in the EPC simulation is drier than the EP simulation in both seasons (Figure 6f), suggesting that it is not a relative humidity enhancement of the aerosol scattering.

[34] We note that these simulations do not include the aerosol indirect effect, and the primary differences in the vertical profile of specific humidity are due to changes in the climate model resolution.

[35] Differences in the sulfate budget (Figure 7b) suggest that the removal processes could be driving the concentration differences in the EP and EPC simulations. The EPC total sulfate burden is greater than $\mathrm{EP}$, with lower production and removal rates in the EPC simulation. Additionally, the net production (e.g., total production rate - total removal rate) for the EPC simulation is greater than the EP simulation, leading to less aerosol removal and hence a greater aerosol burden in the EPC simulation. Because removal rates appear to be a key difference between the EP and EPC simulations and wet removal is the dominant aerosol sink, we examine the precipitation variations between the two simulations.

[36] Figure 12a shows the seasonal cycle of total precipitation for the EP and EPC simulations as compared to gridded precipitation observations from the Climatic Research Unit (CRU) [Mitchell and Jones, 2005]. In general, the EPC simulates less total precipitation than the EP simulation, typically improving agreement with observations in the 
Table 6. Precipitation Averaged by Region and Season for the EP and EPC Simulations and the CRU Data Set (mm/month)

\begin{tabular}{lccccccc}
\hline Species/Season & Domain & Region 1 & Region 2 & Region 3 & Region 4 & Region 5 & Region 6 \\
\hline Precip CRU all & 61.40 & 56.21 & 26.98 & 113.89 & 70.18 & 100.77 \\
Precip EP all & 68.47 & 83.95 & 53.97 & 101.54 & 78.08 & 93.31 \\
Precip EPC all & 63.81 & 74.72 & 46.34 & 102.59 & 79.70 & 97.69 \\
Precip CRU DJF & 51.96 & 85.47 & 17.95 & 140.27 & 55.47 & 128.56 & 96.10 \\
Precip EP DJF & 66.56 & 138.44 & 52.43 & 98.52 & 74.57 & 98.13 & 87.76 \\
Precip EPC DJF & 61.36 & 125.03 & 49.71 & 99.97 & 73.98 & 89.47 & 91.88 \\
Precip CRU JJA & 73.06 & 47.11 & 27.81 & 145.04 & 71.67 & 132.72 & 77.20 \\
Precip EP JJA & 75.61 & 60.85 & 42.45 & 139.55 & 90.29 & 112.36 \\
Precip EPC JJA & 69.45 & 53.93 & 37.68 & 169.58 & 78.55 & 134.55 & 106.95 \\
\hline
\end{tabular}

winter. From the seasonal perspective, the large-scale scheme dominates in the winter with nearly equal contributions of large-scale and convective precipitation in the summer (Figure 12b). Typically, the EPC simulates more convective precipitation in the summer and consistently simulates less large-scale precipitation throughout the seasonal cycle (Table 6). These results are consistent with other studies from both regional [Leung and Qian, 2003; Gao et al., 2006; Rauscher et al., 2010] and global [Fang et al., 2011] models, which find that precipitation tends to increase with an increase in resolution, and is often due to a decrease in the convective precipitation and compensating increases in large-scale precipitation [Rauscher et al., 2010; Duffy et al., 2003]. However, the EPC simulation reduces the precipitation bias in DJF, suggesting that the fine resolution simulation may be overestimating the large-scale contribution of precipitation to the total (Table 6). The largescale precipitation parameterization is developed from measured-modeled evaluations implementing a $60 \mathrm{~km}$ RegCM resolution [Pal et al., 2000], therefore we could expect that climate model simulations with similar resolutions in the parameterization development may lead to lower model biases. While it is possible that differences in aerosol concentrations are driving changes in precipitation, our evaluation of the EP versus ED suggests that changes in resolution is the primary driver of changes in precipitation between the simulations.

[37] The decrease in EPC precipitation increases aerosol concentrations and increases TOA for the EPC simulation throughout the seasonal cycle (Figure 11). The domainaverage TOA for the EPC simulation is $0.08 \mathrm{~W} \mathrm{~m}^{-2}$ greater than the EP simulation, with local differences of up to $5 \mathrm{~W}$ $\mathrm{m}^{-2}$ in the eastern U.S. Unlike the differences between the ED and EP simulations, which were typically in the summertime and likely driven by differences in the emissions and chemical conversion, the difference between the EP and EPC forcing is likely driven by changes in wet removal processes.

[38] To explore the sensitivity of our results to the precipitation parameterizations, we conducted one set of sensitivity tests using an alternative closure option for the Grell convective scheme (changing from the Fritsch-Chappell closure to the Arakawa-Schubert closure). The set includes a 3 -year simulation at $25 \mathrm{~km}$ and one at $60 \mathrm{~km}$. In general, the change in closure scheme caused a $2-4 \%$ decrease in the total precipitation, with small changes in the large-scale precipitation $(\sim 1 \%)$ and greater changes in the convective precipitation (6-26\%). The decreases in the total and largescale precipitation in the coarser model resolution $(60 \mathrm{~km})$ is very similar to our original results. For the convective precipitation, the results are more variable, with an overall decrease in the convective precipitation. Because the largescale precipitation is the greatest controller of wet deposition (large-scale removal was approximately 25 times greater than convective removal in our simulations), we do not expect that this difference in convective precipitation will substantially alter our conclusions about the impact of largescale precipitation on aerosol wet removal. Indeed, changes in the the column burden and TOA in sensitivity tests follows the same pattern seen in the EP and EPC simulations, with a greater impact on the column burden and TOA in the coarse simulations. In addition to model physics, precipitation can be sensitive to land surface scheme selection, depending on the time of year and location [Tawfik and Steiner, 2011]. However, the region with the greatest aerosol burden is not in a strongly land-atmosphere region therefore we do not expect that the aerosol burden would be particularly sensitive to the land surface scheme selection.

[39] To summarize, the EPC simulations have higher concentrations of all aerosols species $\left(\mathrm{SO}_{4}^{2-}, \mathrm{BC}, \mathrm{OC}\right)$ and $\mathrm{AOD}$ in both the surface layer and lower troposphere. The increased $\mathrm{SO}_{4}^{2-}$ is particularly pronounced in the summer, where mean $\mathrm{SO}_{4}^{2-}$ concentrations in EPC can exceed EP by $0.2 \mathrm{ppbm}$. Due to the apparent scale-dependence of the precipitation parameterizations, EP simulates more largescale precipitation than EPC in the summer, which leads to a large removal of aerosol in the EP simulation. In general, wet deposition is the dominant mechanism of sulfate removal in the atmosphere, and the increased precipitation in the EP simulation over the EPC simulation results in $16 \%$ more wet deposition in EP. While there are differences in the convective and large-scale balance of precipitation within the domain, most of the change in wet deposition can be attributed to the magnitude of large-scale precipitation. Based on comparisons with total CRU precipitation, the EPC results provide an improved measured-modeled agreement suggesting that the EPC processes (and higher surface forcings) are likely more realistic. Additionally, the EPC aerosol species regression statistics are slightly better than the EP simulations (Table 5 and Figure 9), suggesting that the EPC precipitation more accurately represents wet deposition processes.

\section{Discussion and Conclusions}

[40] The regional climate model RegCM was used to to determine the importance of the resolution of an emission inventory versus the resolution of the model grid on the 
climate forcing of anthropogenic aerosols over the U.S. RegCM was used to simulate the climate impact of $\mathrm{SO}_{2} /$ $\mathrm{SO}_{4}^{2-}, \mathrm{BC}$ and OC over the U.S. from 1997-2008. Three simulations were completed, one with a $25 \mathrm{~km}$ model grid using the $1^{\circ} \times 1^{\circ}$ EDGAR anthropogenic aerosol emission inventory, another $25 \mathrm{~km}$ simulation, but with the EPA's NEI $4 \times 4 \mathrm{~km}$ emission inventory and a third with with the EPA NEI inventory, but at a $60 \mathrm{~km}$ model grid. The model performance was evaluated against surface measurements of the species concentrations, AOD, and precipitation.

[41] The comparisons of the two emissions inventories (EPA versus EDGAR) showed small differences in primary emissions $\left(\mathrm{SO}_{2}, \mathrm{BC}\right.$ and $\mathrm{OC}$ typically within $\left.15 \%\right)$ and the resulting modeled concentrations. Model $\mathrm{SO}_{2}$ and $\mathrm{SO}_{4}^{2-}$ results for $\mathrm{ED}$ and $\mathrm{EP}$ compare well to concentrations and AOD observations in winter, suggesting that emission inventories sufficiently capture most major sources. However, the measurement/model agreement was reduced in the summer with an overestimation of $\mathrm{SO}_{2}$ and underestimation of $\mathrm{SO}_{4}^{2-}$, indicating insufficient conversion of $\mathrm{SO}_{2}$ to $\mathrm{SO}_{4}^{2-}$ in accordance with previous findings [Solmon et al., 2006]. For BC, the EP surface concentrations were closer to observations than ED BC surface concentrations, though both inventories underestimated $\mathrm{BC}$ by $58 \%$ (72\%) for EP (ED) in DJF and by $78 \%(85 \%)$ in JJA. A sensitivity test of the magnitude of the $\mathrm{BC}$ emissions indicated that the EPA inventory is missing BC sources, particularly in the summer time, likely due to the lack of biomass burning in the inventory. Surface OC concentrations in both EPA and EDGAR simulations were underestimated by $77 \%$ in DJF and $98 \%$ in JJA, likely due to the lack of biogenic organics. Finally, the EP simulation slightly improved measuredmodeled agreement for AOD compared to the ED simulation. Because the majority of the modeled AOD is driven by the $\mathrm{SO}_{4}^{2-}$, the lack of summertime $\mathrm{SO}_{4}^{2-}$ and $\mathrm{OC}$ contribute to the AOD underestimates in JJA. Overall, the EP simulations consistently showed marginal improvement based on measured-modeled metrics as compared to the ED simulations, though the improvements were not as large as the difference in the magnitude of emissions. Despite similarities in the surface aerosol concentrations, differences in the JJA climate response is notable between the two inventories. The ED inventory leads to slightly higher sulfate concentrations throughout the vertical profile, which leads to an increased TOA for the EDGAR inventory in the summertime.

[42] Comparisons of the $25 \mathrm{~km}$ (EP) and $60 \mathrm{~km}$ (EPC) simulations show than a decrease in resolution increases surface concentrations of all species, leading to an increased aerosol burden and TOA forcing of about $2.5 \mathrm{Wm}^{-2}$ in JJA. The resolution-driven change in the magnitude of JJA TOA forcing is similar to the change caused by different emissions inventories. For all aerosol species $\left(\mathrm{SO}_{4}^{2-}, \mathrm{BC}\right.$ and OC), the EPC simulation provides better agreement with observations than the EP simulation due to higher concentrations of these species throughout most of the lower troposphere. Vertical profiles of AOD (Figure 9e) indicate that most of the extinction is due to the sulfate aerosol, and EPC $\mathrm{SO}_{4}^{2-}$ concentrations are substantially larger than the EP concentrations throughout the vertical profile. An examination of the sulfate budget shows that while more $\mathrm{SO}_{2}$-to- $\mathrm{SO}_{4}^{2-}$ conversion is occurring in the EP simulation, the differences in the two simulations are driven by the loss processes, notably the wet deposition due to large-scale precipitation. Less deposition in the coarse simulations result in higher sulfate concentrations throughout the vertical profile, leading to greater extinction and higher surface forcings. Because the precipitation biases are reduced in the EPC simulations, the coarse scale estimation of precipitation and wet removal may provide a better estimate of present-day climate.

[43] In conclusion, evaluations of modeled aerosol concentrations, AOD and precipitation suggest that that climate model resolution and emissions inventory can have an important impact on modeled aerosol forcings via scaledependent precipitation parameterizations. Our results find that wet removal of aerosols is very dependent on the ratio of convective and large-scale precipitation simulated by the model. As we note above, many of these parameterizations are tuned for specific resolution, and changing resolution without precipitation tuning may lead to large changes in the aerosol burden. Therefore, when considering changes in model resolution, the precipitation parameterizations play a key role in regional simulations of atmospheric aerosols and chemistry-climate feedbacks. These findings are relevant for other atmospheric pollutants and global scale models as well [e.g., Fang et al., 2011]. While there are clearly many shortcomings in these simulations, notably the absence of biomass burning emissions and secondary organic aerosol formation, the results suggest a scale dependence that has not been closely examined in the literature. Because the differences in the precipitation ultimately affect the computed surface forcings, selection of model resolution may have a greater impact on surface forcing than the selection of the emissions inventory and missing emission sources. These results suggest that future climate model studies should carefully examine scale-dependent precipitation processes, particularly those related to precipitation and wet removal, as these processes strongly affect aerosol concentrations and resulting surface forcings.

[44] Acknowledgments. We thank Ahmed Tawfik (University of Michigan), Fabien Solmon (ICTP), Ashraf Zakey (DMI), and the ICTP RegCNET for providing simulation support on RegCM simulations. Additionally, we gratefully acknowledge MOZART boundary conditions provided by Louisa Emmons (NCAR). Measurement data were provided by the CASTNET, IMPROVE, and AERONET data networks, and we thank the network supporters for providing this data to the public. We thank Greg Frost and Stuart McKeen for processed NEI inventories prepared from EPA emissions files. Finally, we wish to thank the three reviewers, who provided a thorough review and many comments which helped improve the quality of this paper.

\section{References}

Appel, K. W., K. M. Foley, J. O. Bash, R. W. Pinder, R. L. Dennis, D. J. Allen, and K. Pickering (2010), A multi-resolution assessment of the Community Multiscale Air Quality (CMAQ) Model v4.7 wet deposition estimates for 2002-2006, Geosci. Model Dev. Discuss., 3(4), 2315-2360, doi:10.5194/gmdd-3-2315-2010.

Bian, H., M. Chin, J. M. Rodriguez, H. Yu, J. E. Penner, and S. Strahan (2009), Sensitivity of aerosol optical thickness and aerosol direct radiative effect to relative humidity, Atmos. Chem. Phys., 9(7), 2375-2386, doi:10.5194/acp-9-2375-2009.

Bond, T. C., E. Bhardwaj, R. Dong, R. Jogani, S. Jung, C. Roden, D. Streets, S. Fernandes, and N. Trautmann (2007), Historical emissions of black and organic carbon aerosol from energy-related combustion, 1850-2000, Global Biogeochem. Cycles, 21, GB2018, doi:10.1029/ 2006GB002840. 
Cooke, W. F., C. Liousse, H. Cachier, and J. Feichter (1999), Construction of a $1^{\circ} \times 1^{\circ}$ degree fossil fuel emission data set for carbonaceous aerosol and implementation and radiative impact in the echam 4 model, J. Geophys. Res., 104, 22,137-22,162.

Duffy, P. B., B. Govindasamy, J. P. Iorio, J. Milovich, K. R. Sperber, K. E. Taylor, M. F. Wehner, and S. L. Thompsonn (2003), Highresolution simulations of global climate, part 1: present climate, Clim. Dyn., 19, 371-390.

Ekman, A., and H. Rodhe (2003), Regional temperature response due to indirect sulfate aerosol forcing: impact of model resolution, Clim. Dyn. 21, 1-10, doi:10.1007/s00382-003-0311-y.

Emmons, L. K., et al. (2010), Description and evaluation of the Model for Ozone and Related chemical Tracers, version 4 (MOZART-4), Geosci. Model Dev., 3(1), 43-67, doi:10.5194/gmd-3-43-2010.

Fang, Y., et al. (2011), The impacts of changing transport and precipitation on pollutant distributions in a future climate, J. Geophys. Res., 116 D18303, doi:10.1029/2011JD015642.

Fernandes, S. M., N. M. Trautmann, D. G. Streets, C. Roden, and T. Bond (2007), Global biofuel use, 1850-2000, Global Biogeochem. Cycles, 21, GB2019, doi:10.1029/2006GB002836.

Frost, G. J., et al. (2006), Effects of changing power plant $\mathrm{NO}_{x}$ emissions on ozone in the eastern United States: Proof of concept, J. Geophys. Res., 111, D12306, doi:10.1029/2005JD006354.

Gao, X., J. S. Pal, and F. Giorgi (2006), Projected changes in mean and extreme precipitation over the Mediterranean region from a high resolution double nested RCM simulation, Geophys. Res. Lett., 33, L03706, doi:10.1029/2005GL024954.

Ginoux, P., L. W. Horowitz, V. Ramaswamy, I. V. Geogdzhayev, B. H. Holben, G. Stenchikov, and X. Tie (2006), Evaluation of aerosol distribution and optical depth in the Geophysical Fluid Dynamics Laboratory coupled model for CM2.1 for present climate, J. Geophys. Res., 111, D22210, doi:10.1029/2005JD006707.

Giorgi, F. (1989), Two-dimensional simulations of possible mesoscale effects of nuclear war fires. I: model description, J. Geophys. Res., 94 $1127-1144$.

Giorgi, F., and W. L. Chameides (1986), Rainout lifetimes of highly soluble aerosols and gases as inferred from simulations with a general circulation model, J. Geophys. Res., 91, 14,367-14,376.

Giorgi, F., X. Bi, and Y. Qian (2002), Direct radiative forcing and regional climatic effects of anthropogenic aerosols over East Asia: A regional coupled climate-chemistry/aerosol model study, J. Geophys. Res., 107(D20), 4439, doi:10.1029/2001JD001066.

Grell, G. A. (1993), Prognostic evaluation of assumptions used by cumulus parameterizations, Mon. Weather Rev., 121, 764-787.

Grell, G. A., J. Dudhia, and D. R. Stauffer (1994), A description of the fifthgeneration Penn State-NCAR Mesoscale Model (MM5), NCAR Tech. Note NCAR/TN-398+STR, 122 pp., Natl. Cent. for Atmos. Res., Boulder, Colo.

Hansen, J., M. Sato, P. Kharecha, G. Russell, D. W. Lea, and M. Siddall (2007a), Climate change and trace gases, Philos. Trans. R. Soc. A, 365 (1856), 1925-1954, doi:10.1098/rsta.2007.2052.

Hansen, J., et al. (2007b), Climate simulations for 1880-2003 with GISS modelE, Clim. Dyn., 29, 661-696, doi:10.1007/s00382-007-0255-8.

Holben, B., et al. (1998), AERONET-A federated instrument network and data archive for aerosol characterization, Remote Sens. Environ., 66(1), 1-16, doi:10.1016/S0034-4257(98)00031-5.

Holtslag, A. A. M., E. I. F. de Bruijin, and H. L. Pan (1990), A high resolution air mass transformation model for short-range weather forecasting, Mon. Weather Rev, 118, 1561-1575.

Intergovernmental Panel on Climate Change (IPCC) (2007), Climate Change 2007: The Physical Science Basis. Contribution of Working Group I to the Fourth Assessment Report of the Intergovernmental Panel on Climate Change, Cambridge Univ. Press, New York.

Jaffe, D., S. Tamuraa, and J. Harrisb (2005), Seasonal cycle and composition of background fine particles along the west coast of the US, Atmos. Environ., 39, 297-306.

Jimenez, J. L., et al. (2009), Evolution of organic aerosols in the atmosphere, Science, 326, 1525-1529.

Kalnay, E., et al. (1996), The NCEP/NCAR 40-year reanalysis project, Bull. Am. Meteorol. Soc., 77, 437-471.

Kasibhatla, P., W. L. Chameides, and J. S. John (1997), A three dimensional global model investigation of seasonal variation in the atmospheric burden of anthropogenic sulfate aerosols, J. Geophys. Res., 102, 3737 3759.

Kiehl, J. T., J. J. Hack, G. B. Bonan, B. A. Boville, B. P. Briegleb, D. Williamson, and P. Rasch (1996), Description of the NCAR Community Climate Model (CCM3), NCAR Tech. Note NCAR/TN-420+STR, 152 pp., Natl. Cent. for Atmos. Res., Boulder, Colo.
Kim, S.-W., et al. (2009), NO2 columns in the western United States observed from space and simulated by a regional chemistry model and their implications for NOx emissions, J. Geophys. Res., 114, D11301, doi:10.1029/2008JD011343.

Lawrence, P. J., and T. N. Chase (2007), Representing a new MODIS consistent land surface the Community Land Model (CLM 3.0), J. Geophys. Res., 112, G01023, doi:10.1029/2006JG000168.

Leung, L. R., and Y. Qian (2003), Changes in seasonal and extreme hydrologic conditions of the Georgia Basin/Puget Sound in an ensemble regional climate simulation for the mid-Century, Can. Water Resour., $28,605-632$.

Luo, C., Y. Wang, S. Mueller, and E. Knipping (2011), Diagnosis of an underestimation of summertime sulfate using the Community Multiscale Air Quality model, Atmos. Environ., 45, 5119-5130.

Malm, W. C., B. A. Schichtel, M. L. Pitchford, L. L. Ashbaugh, and R. A. Eldred (2004), Spatial and monthly trends in speciated fine particle concentration in the United States, J. Geophys. Res., 109, D03306, doi:10.1029/2003JD003739.

Matsui, T., and R. A. Pielke (2006), Measurement-based estimation of the spatial gradient of aerosol radiative forcing, Geophys. Res. Lett., 33, L11813, doi:10.1029/2006GL025974.

Mitchell, T. D., and P. D. Jones (2005), An improved method of constructing a database of monthly climate observations and associated highresolution grids, Int. J. Climatol., 25, 693-712.

National Research Council (2005), Radiative Forcing of Climate Change: Expanding the Concept and Addressing Uncertainties, Natl. Acad. Press, Washington, D. C.

Olivier, J., J. A. V. Aardenne, F. Dentene, L. Ganzeveld, and J. Peters (2005), Recent trends in global greenhouse gas emissions: Regional trends and spatial distribution of key sources, in Non- $\mathrm{CO}_{2}$ Greenhouse Gases (NCGG-4), edited by A. van Amstel, pp. 325-330, Millpress, Rotterdam, Netherlands.

Pal, J. S., E. E. Small, and E. A. B. Eltahir (2000), Simulation of regionalscalewater and energy budgets: Representation of subgrid cloud and precipitation processes within regcm, J. Geophys. Res., 105, 579-594.

Pal, J. S., et al. (2009), The ICTP RegCM3 and RegCNET: Regional climate modeling for the developing world, Bull. Am. Meteorol. Soc., 88, 1395.

Park, R. J., D. J. Jacob, M. Chin, and R. V. Martin (2003), Sources of carbonaceous aerosols over the United States and implications for natural visibility, J. Geophys. Res., 108(D12), 4355, doi:10.1029/ 2002JD003190.

Qian, Y., and F. Giorgi (1999), Interactive coupling of regional climate and sulfate aerosol models over eastern Asia, J. Geophys. Res., 104, 6477-6499.

Qian, Y., F. Giorgi, and Y. Huang (2001), Regional simulation of anthropogenic sulfur over east Asia and its sensitivity to model parameters, Tellus, Ser. B, 53, 171-191.

Qian, Y., W. I. Gustafson Jr., and J. D. Fast (2010), An investigation of the sub-grid variability of trace gases and aerosols for global climate modeling, Atmos. Chem. Phys., 10(14), 6917-6946, doi:10.5194/acp10-6917-2010.

Ramanathan, V., et al. (2005), Atmospheric brown clouds: Impacts on South Asian climate and hydrological cycle, Proc. Natl. Acad. Sci. U. S. A., 102, 5326-5333.

Rasch, P. J., M. Barth, J. T. Kiehl, C. M. Benkovitz, and S. E. Schwartz (2000), A description of the global sulfur cycle and its controlling processes in the National Center for Atmospheric Research Community Climate Model, J. Geophys. Res., 105, 1367-1385, doi:10.1029/ 1999JD900777.

Rauscher, S., E. Coppola, C. Piani, and F. Giorgi (2010), Resolution effects on regional climate model simulations of seasonal precipitation over Europe, Clim. Dyn., 35, 685-711, doi:10.1007/s00382-009-0607-7.

Reynolds, R. W., N. A. Rayner, T. M. Smith, D. C. Stokes, and W. Q. Wang (2002), An improved in situ and satellite SST analysis for climate, J. Clim., 15, 1609-1625.

Shindell, D., and G. Faluvegi (2009), Climate response to regional radiative forcing during the twentieth century, Nat. Geosci., 2, 294-300, doi:10.1038/ngeo473.

Shindell, D., H. Levy, M. D. Schwarzkopf, L. W. Horowitz, J.-F. Lamarque, and G. Faluvegi (2008), Multimodel projections of climate change from short-lived emissions due to human activities, J. Geophys. Res., 113, D11109, doi:10.1029/2007JD009152.

Solmon, F., F. Giorgi, and C. Liousse (2006), Aerosol modelling for regional climate studies: Application to anthropogenic particles and evaluation over a European/African domain, Tellus, Ser. B, 58, 51-72.

Steiner, A. L., J. S. Pal, S. A. Rauscher, J. L. Bell, N. S. Diffenbaugh, A. Boone, L. C. Sloan, and F. Giorgi (2009), Land surface coupling in 
regional climate simulations of the West African monsoon, Clim. Dyn. 98, 293-314, doi:10.1007/s00382-009-0543-6.

Stroud, C. A. et al. (2010), Impact of model grid spacing on regional- and urban-scale air quality predictions of organic aerosol, Atmos. Chem. Phys., 10(12), 30,347-30,379.

Tan, Q., Y. Huang, and W. L. Chameides (2002), Budget and export of anthropogenic $\mathrm{SO}_{x}$ from east Asia during continental outflow conditions, J. Geophys. Res., 107(D13), 4167, doi:10.1029/2001JD000769.

Tawfik, A., and A. Steiner (2011), The role of soil ice in land-atmosphere coupling over the United States: A soil moisture-precipitation winter feedback mechanism, J. Geophys. Res., 116, D02113, doi:10.1029/ 2010JD014333

U.S. Environmental Protection Agency (2011), Inventory of U.S. greenhouse gas emissions and sinks: 1990-2009, Tech. Rep. EPA 430-R-11005, Washington, D. C. van Aardenne, J. A., F. Dentener, J. Olivier, and J. Peters (2005), The EDGAR 3.2 Fast Track 2000 dataset (32FT2000), technical report, Inst. for Environ. and Sustainability, Joint Res. Cent., Ispra, Italy.

Walker, M., and N. Diffenbaugh (2009), Evaluation of high-resolution simulations of daily-scale temperature and precipitation over the United States, Clim. Dyn., 33, 1131-1147, doi:10.1007/s00382-009-0603-y.

Wild, O., and M. J. Prather (2006), Global tropospheric ozone modeling Quantifying errors due to grid resolution, J. Geophys. Res., 111, D11305, doi:10.1029/2005JD006605.

R. C. Owen, Michigan Tech Research Institute, Michigan Technological University, Ann Arbor, MI 48105, USA. (rcowen@mtu.edu)

A. L. Steiner, Department of Atmospheric, Oceanic, and Space Sciences, University of Michigan, Ann Arbor, MI 48105, USA. (alsteiner@umich. edu) 